\title{
Lanthanum phosphate: An efficient catalyst for acrylic acid production through lactic acid dehydration
}

\author{
Nekkala Nagaraju ${ }^{\mathrm{a}}$, Putrakumar Balla ${ }^{\mathrm{b}}{ }^{*}$, Ginjupalli Srinivasarao ${ }^{\mathrm{c}}$, Seelam Prem Kumar ${ }^{\mathrm{d}}$, SK \\ Hussain $^{\mathrm{a}}$, Ponnala Bhanuchander ${ }^{\mathrm{a}}$, K.V. Chary ${ }^{\mathrm{a}}$ \\ a- Catalysis Division, Indian Institute of Chemical Technology, Hyderabad, India \\ b- School of Materials Science and Engineering, Jiangxi University of Science and \\ Technology, Ganzhou, China,341000 \\ c- Basic Science and Humanities Department, Swarnandhra College of Science and \\ Technology, Narasapur, 534280, India. \\ d- Environmental and Chemical Engineering Research Unit, Faculty of Technology, \\ P.O. Box 4300, University of Oulu, Finland
}

\begin{abstract}
In this work, biomass-based platform molecule lactic acid conversion to acrylic acid has been studied. A series of Lanthanum phosphate ( $\mathrm{LaP})$ catalysts prepared by varying the lanthanum to phosphorus (La/P) mole ratio (i.e. 0.2, 0.35, 0.5, 1.0 and 2.0) and also prepared at different calcination temperatures (i.e. 400, 500, 600 and $800^{\circ} \mathrm{C}$ ) were investigated. The prepared catalysts were characterised by using different techniques and tested in the dehydration of lactic acid (LA) to acrylic acid (AA) production. All the synthesized catalysts were characterized to understand the physico-chemical properties such as degree of crystallinity, total surface acidity, specific surface area and morphology were analysed. The $\mathrm{NH}_{3}-\mathrm{TPD}$ results imply that, all the catalysts exhibited varied amount of total acidity, mostly weak acid sites, with the phosphate loading. The weak acid sites which are mainly Lewis acid sites played an important role in producing AA selectively and efficiently from the LA conversion. The most optimized reaction conditions were determined to obtain highest LA conversion, selectivity, and AA yield. The
\end{abstract}


catalyst with $\mathrm{La} / \mathrm{P}$ mole ratio 0.35 and calcined at $500{ }^{\circ} \mathrm{C}$, exhibited best performance with complete LA conversion, AA selectivity of $\sim 74 \%$ and a maximum yield of AA $74 \%$ was achieved. Furthermore, the $\operatorname{LaP}(0.35)[500]$ catalyst was successfully tested for three different time on streams and found to be stable.

\section{Introduction}

Currently crude oil is being used extensively in producing high performance fuels and chemicals. Today, globally around $70 \%$ of crude oil is consumed in producing fuels and $20 \%$ is being utilized in producing various chemicals and intermediate compounds [1]. The demand for chemical feedstocks is increasing tremendously with economy in developing countries. The most important global concerns are the climate change and environmental pollution due to fossil-based products. Biomass based refinery and chemicals production can lead to a sustainable society due to its abundance and whole process works under closed carbon cycle. The utilization of lignocellulose as a chemical feedstock found to be an efficient and viable alternative to fossil based raw materials. Moreover, lignocellulose materials are economically and ecologically attractive to produce highly value-added chemicals and intermediates, which are usually produced in low volumes compared to transport fuels [2-4]. Furthermore, it is more advantageous to convert oxygen rich lignocellulosic material to 'drop-in' renewable chemicals that are molecularly identical to conventional petrochemical chemicals. The renewable fuels requires more energy and high operating costs to remove oxygen from the biofuels. The foreseeable future for biorefineries to be economically viable is a challenge in manufacturing high-value chemicals and intermediates, besides low value biofuels [5]. The efficient production of 'drop-in' renewable chemicals can be achieved by using the existing infrastructure and valuechain, thus provide more incentives in terms of energy efficiency with low or zero carbon 
emissions. In this context, one such chemical produced from biorefinery is the lactic acid, as a platform molecule used in manufacturing of many valuable compounds. Acrylic acid (AA) is considered to be one of the most promising renewable chemicals produced from Lactic acid (LA), because of the bio-based platform molecule and the possibility to produce in large volumes from lignocellulose. Generally, lactic acid (2-hydroxy propionic acid) was derived from the biomass feedstock and LA is an important building block in producing highly valuable chemicals such as AA, acetaldehyde (AD), acetic acid, 1,2-propane-diol, biodegradable poly lactides etc. [6-7] (scheme 1).

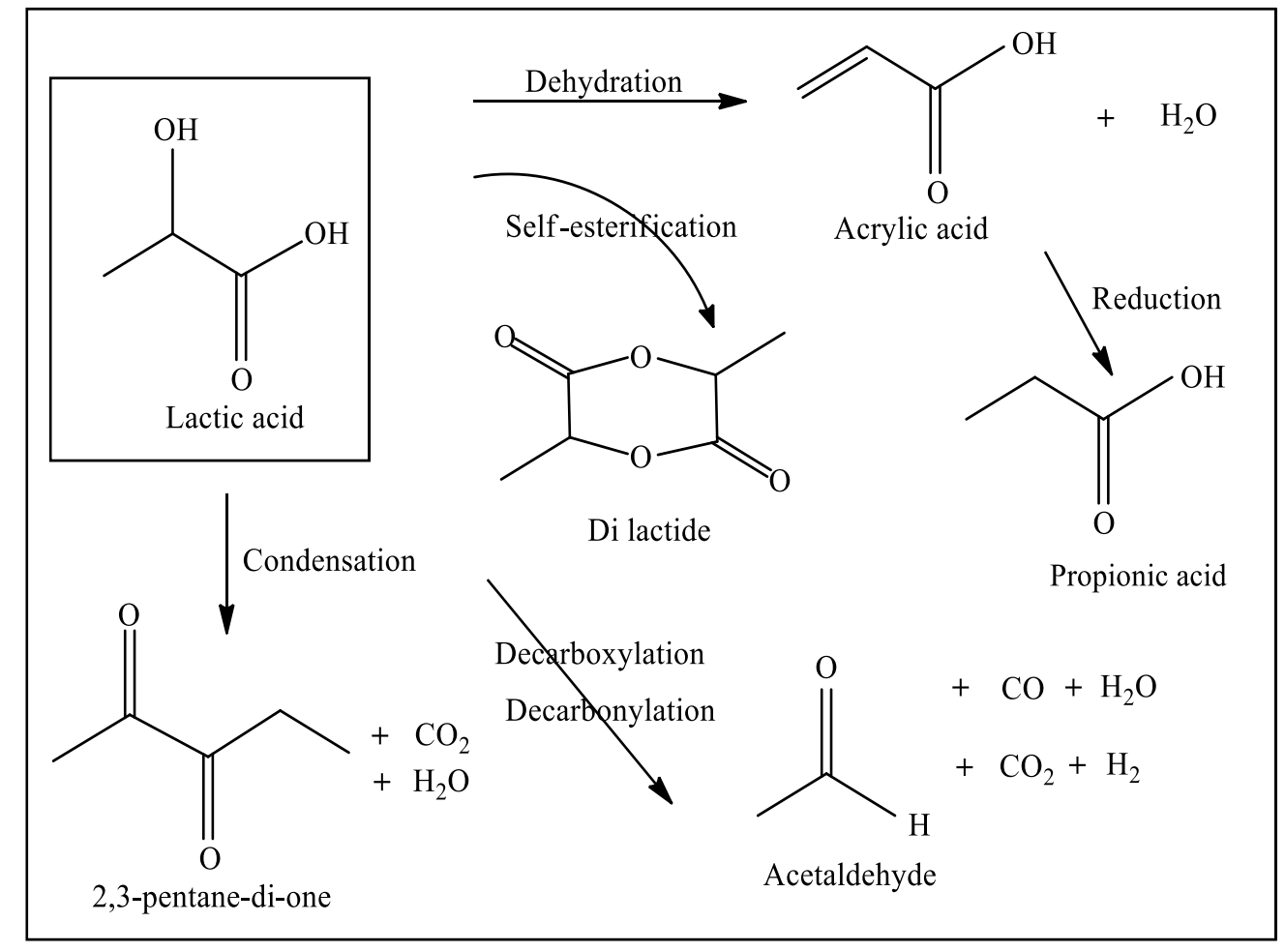

Scheme 1. Lactic acid conversion routes to various reaction products.

Lactic acid produced via fermentation of sugars such as glucose, starch [8], cellulose [910], hemicelluloses [11] and also from glycerol through biochemical processes [12-14]. Among many products produced from the lactic acid conversion, acrylic acid (AA) is one of the 
important chemicals used in production of polymers. Recently, AA received much attention due to its wide variety of applications such as acrylate polymers (which are used in the manufacturing of paint adhesives, textiles, and leather treating agents) [15-16]. Currently AA is produced industrially by selective catalytic oxidation of propylene in a two-step processes, first step involves propane conversion to propylene, and in the final step, the propylene to AA [17]. Globally, propylene is produced from fossil-based feedstock and thus, contributing to carbon emissions. Henceforth, AA can be produced by using renewable feedstock through gas-phase dehydration of LA, which is an environmentally benign process [18].

Catalytic conversion of LA to AA was studied extensively over different heterogeneous solid catalysts and support materials such as alkali and alkaline earth metal sulphates [19-21], phosphates [22-25], rare earth metal phosphates [26-27], hydroxyapatites [28-31] and various types of alkali and alkaline earth metals modified zeolites [32-37]. Majority of these investigations reported that the dehydration of LA efficiently catalyzed over solid acid-base catalysts, which are typically with different acidity strength such as weak acidic and basic sites [26-29].

Moreover, the catalysts which exhibiting strong acidity strength are favorable in decarbonylation/decarboxylation step to yield acetaldehyde [38-39], which is a major byproduct formation during LA conversion. However, LA conversion over the catalysts with strong basicity produces wide variety of byproducts [32]. Most of the recent studies are focused on using alkali and alkaline earth metal sulphates, phosphates, and zeolites due their desired physico-chemical properties and cost [19-32]. However, there are no studies reported on using rare earth metal phosphates as catalysts. Rare earth metal phosphates have been gaining considerable attention in recent years as catalysts due to their easy preparation, unique properties such as high thermal 
stability, melting point, high acidity, and moderate surface area [40-41]. Moreover, metal phosphate catalysts are already employed in various reactions such as alkylation of phenol, dehydration of alcohols, oxidative dehydrogenation, etc. [42-43]. In our previous study, we reported on cerium phosphate catalysts for lactic dehydration reaction and found to be active and selective [26]. In this work we prepared and designed lanthanum phosphate (LaP) based catalysts for the dehydration of LA reaction by varying the La/P mole ratios, which is the novelty of this work.

Recently Guo et al. 2016, prepared lanthanum phosphate nano rods using n-butyl amine as a shape directing agent (SDA) for lactic acid dehydration. ${ }^{[41]}$ The acidity of the catalysts varied due to the molar ratio of SDA to lanthanum, and able to achieve maximum LA conversion of $72 \%$ and nearly $50 \%$ AA selectivity. In this work, we are able to achieve superior catalytic performance with almost complete LA conversion and better AA selectivity of 74\% than Zhen et al. 2020. The LaP catalysts are prepared with simple co-precipitation method with varying amounts of lanthanum to phosphorous molar ratio and also studied the effect of calcination temperature.

\section{Experimental}

\subsection{Materials \& catalyst synthesis}

All reagents are of analytical grade i.e. Lanthanum nitrate hexahydrate, ortho phosphoric acid $(86 \% \mathrm{v} / \mathrm{v})$, ammonium hydroxide solution (v/v 25\%) and lactic acid are purchased from Sigma USA. The series of LaP catalysts were synthesized based on the method reported by Li et al. [44]. According to the method described in $\mathrm{Li}$ et al. [44] a series of LaP catalysts $\left(\mathrm{LaNO}_{3} \cdot 6 \mathrm{H}_{2} \mathrm{O}+86 \% \mathrm{H}_{3} \mathrm{PO}_{4}\right)$ were prepared by precipitation method using $10 \%$ aqueous 
ammonia as a precipitating agent $\left(\mathrm{P}^{\mathrm{H}} \sim 10\right)$. In this work, the catalysts are prepared by varying the La/P mole ratio (i.e. $0.2,0.35,0.5,1.0 \& 2.0)$ and then, the catalysts are calcined at different temperatures (i.e. $\left.400,500,600 \& 800{ }^{\circ} \mathrm{C}\right)$. The catalysts are denoted as $\mathrm{LaP}(\mathrm{m})[\mathrm{T}]$, where ' $\mathrm{m}$ ' represents $\mathrm{La} / \mathrm{P}$ mole ratio and ' $\mathrm{T}$ ' represents calcination temperature. The catalysts containing different mole ratios were prepared by using different amounts of phosphoric acid and keeping La amount constant. Therefore, La/P mole ratios were changed according to the amount of phosphate loadings during the synthesis.

\subsection{Materials characterization}

All the prepared catalysts were characterized to understand the physico-chemical properties such as phase composition, crystallinity, total acidity, surface area, and morphology using ammonia temperature programmed desorption ( $\left.\mathrm{NH}_{3}-\mathrm{TPD}\right), \mathrm{N}_{2}$ sorption, SEM, XRD, and FTIR techniques respectively.

The powder X-ray diffraction was performed on Ultima IV diffractometer (Rigaku Corporation, Japan) using $\mathrm{Ni}$ filtered $\mathrm{Cu} \mathrm{K} \alpha$ radiation $\left(\lambda=1.5406 \mathrm{~A}^{\circ}\right)$ operated at $40 \mathrm{kV}$ and $30 \mathrm{~mA}$. The measurements were recorded at $2 \theta=10^{\circ}-80^{\circ}$ with a scanning rate of $5 \% \mathrm{~min}$. The FTIR spectra of self-supporting disks of powder dispersed in $\mathrm{KBr}$ were recorded at room temperature on a Bruker TENSOR 27 spectrometer in the range of $400-3500 \mathrm{~cm}^{-1}$. The specific surface areas were measured by $\mathrm{N}_{2}$ physisorption at liquid nitrogen temperature over Autosorb1C instrument (Quantachrome instruments, USA). Prior to the adsorption the samples were degassed under vacuum at $350{ }^{\circ} \mathrm{C}$ for $8 \mathrm{~h}$ and the specific surface area was estimated using multipoint BET method. 
The morphological features of samples were obtained by scanning electron microscope (SEM) (Model: EVO 18, Carl Zeiss) device. Prior to SEM analysis, the samples were sprinkled on $1 \mathrm{~cm}$ stub stacked with a double-sided carbon tape and it was sputter coated in a sputter chamber with gold target to avoid charging and the stub is fixed in the SEM instrument. The elemental composition of the lanthanum phosphate catalysts were determined by Energy Dispersive X-ray spectroscopy (EDS) equipped with SEM instrument (EDS-EVO 18 Oxford instrument), thus, this enables to find the actual metal to phosphorous mole ratio in the sample.

The surface acidity of the catalyst samples were determined by temperature programmed desorption (TPD) analysis using AutoChem 2910 (M/s Micromeritics, USA) instrument with $\mathrm{NH}_{3}$ as a probe molecule. In a typical experiment, $\sim 50 \mathrm{mg}$ dried sample was mounted between quartz wool in a U-shaped quartz tube. The sample was preheated at $300{ }^{\circ} \mathrm{C}$ for $1 \mathrm{~h}$ under high purity $\mathrm{He}(50 \mathrm{~mL} / \mathrm{min})$ flow before adsorption of $\mathrm{NH}_{3} / \mathrm{CO}_{2}$ at $100{ }^{\circ} \mathrm{C}$ for $30 \mathrm{~min}$. The physisorbed $\mathrm{NH}_{3}$ was removed by treating the sample at $100{ }^{\circ} \mathrm{C}$ for $30 \mathrm{~min}$ under $\mathrm{He}$ flow $(50 \mathrm{~mL} / \mathrm{min})$. Finally, the amount of chemically adsorbed $\mathrm{NH}_{3}$ was estimated using TCD detector by desorbing the probe gas by heating the sample from $100{ }^{\circ} \mathrm{C}$ to $700{ }^{\circ} \mathrm{C}$ at a heating rate of $10^{\circ} \mathrm{C} / \mathrm{min}$ under He flow $(50 \mathrm{~mL} / \mathrm{min})$.

Thermogravimetric analysis (TGA) analysis was conducted by using TA instruments Q500. The sample heated under air at room temperature to $800{ }^{\circ} \mathrm{C}$ at a heating rate of $10{ }^{\circ} \mathrm{C} / \mathrm{min}$. However, the amount of carbon deposited over the surface of the used catalysts were determined by using CHNS Analyzer-ELEMENTAR Vario microcube model by determining the elemental compositions.

\subsection{Catalytic reaction}


The prepared catalysts tested in the dehydration of LA under vapor phase conditions at atmospheric pressure. Prior to the reaction, $500 \mathrm{mg}$ of catalyst with mesh size $20-40 \mathrm{~mm}$ pellets are diluted with glass beads and packed in the middle section of the reactor $(300 \mathrm{~mm}$ length and $14 \mathrm{~mm}$ inner diameter) using quartz wool. Molecular sieves were placed above the catalyst bed to provide as a pre-heating zone to vaporize the lactic acid feed. About $30 \mathrm{wt} \%$ aqueous lactic acid solution was fed into the pre-heating zone over the catalyst bed using a pump (perfusor FM Infusion by BRAUN, Germany) under nitrogen flow (30 mL/min). The condensed products were collected using ice-trap and then analyzed by GC (Shimadzu GC 2014 equipped with DB-wax column: $30 \mathrm{~m} \times 0.32 \mathrm{~mm}$ ) connected to flame ionization detector (FID). The condensed products were also analyzed by using GC-MS (HP-5973 quadruple equipped with HP-1MS) with capillary column $(15 \mathrm{~m} \times 0.25 \mathrm{~mm})$. The non-condensable tail gases were identified using GC (Shimadzu GC 2014) equipped with molecular sieve-5A packed column $(2 \mathrm{~m} \times 2 \mathrm{~mm}$, mesh-60/80) connected to TCD detector. The LA conversion, products selectivity and yield were calculated by using the following equations (1-3).

$$
\begin{aligned}
& \text { LA conversion }(\%)=\frac{\text { moles of LA consumed }}{\text { moles of LA in the feed }} \times 100 \text {--- } \\
& \text { Products seelctivity }(\%)=\frac{\text { moles of } C \text { atoms in the specified product }}{\text { moles of C atoms in LA consumed }} \times 100 \text {----------(2) } \\
& \text { Products yield }(\%)=\frac{\text { LA conversion } \times \text { specified product selectivity }}{100}
\end{aligned}
$$

\section{Results and discussion}

\subsection{Characterization results}

The EDS analysis of the LaP samples presented in the Figure 1, the spectra indicate that the samples containing lanthanum and phosphorous as the major phases. The different La/P mole 
ratios were analyzed by EDS analysis and the ratios are presented in Table 1 and results confirmed that the metal content values are well in agreement with the nominal La/P mole ratios. The BET surface areas and textural properties of the catalysts were summarized in the Table S1. The specific surface areas increased slightly from $64.3 \mathrm{~m}^{2} / \mathrm{g}$ to $71.2 \mathrm{~m}^{2} / \mathrm{g}$ with $\mathrm{La} / \mathrm{P}$ mole ratio and then declines (i.e. as the phosphate amount increases) from 2.0 to 0.5 . Further the surface area decreasing trend was observed in the samples with the $\mathrm{La} / \mathrm{P}$ mole ratios from 0.35 to 0.2 . Moreover, the surface area decreased with the calcination temperature from 500 to $800{ }^{\circ} \mathrm{C}$. The sample calcined at higher temperature $\left(800{ }^{\circ} \mathrm{C}\right)$ is having the lowest surface area of $6.1 \mathrm{~m}^{2} / \mathrm{g}$. Generally, calcination treatment decreases the surface area of the samples due to the structural or phase changes occurred during thermal treatment, which can also be observed from the XRD results.
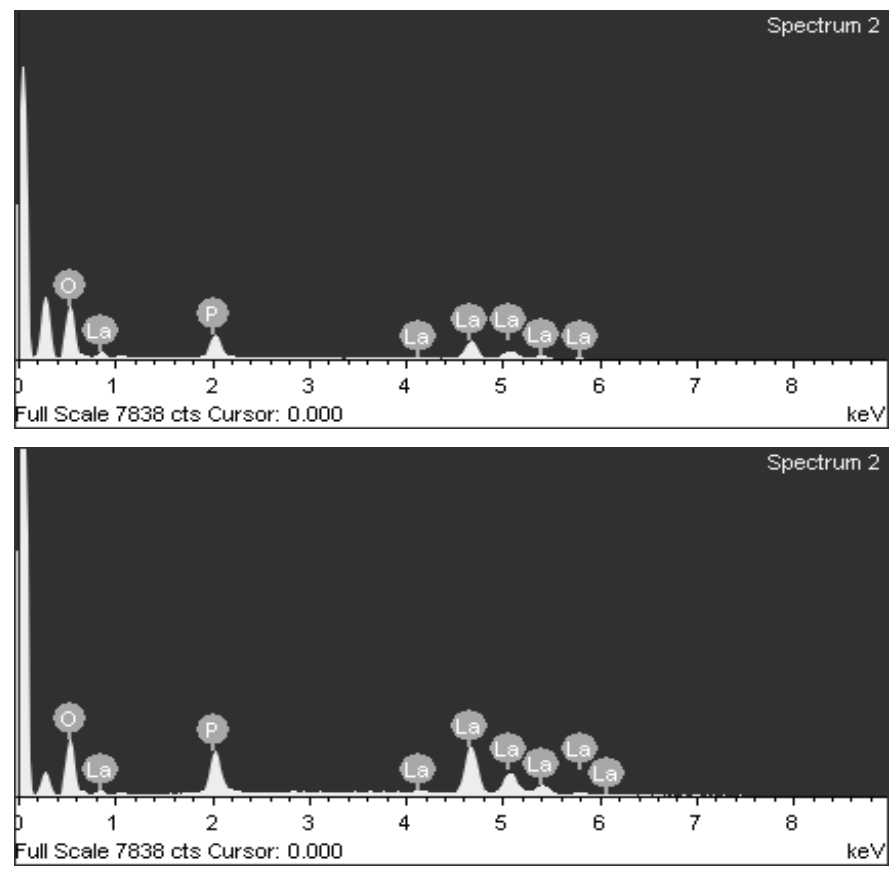

Figure 1. EDS spectra of lanthanum phosphate samples a) $\mathrm{LaP}(0.35)[500]$ and b) $\operatorname{LaP}(1.0)[500]$ 
Table 1: Catalytic properties of different LaP-based catalysts.

\begin{tabular}{cccc}
\hline Catalyst & La/P mole ratio & $\begin{array}{c}\text { a } \\
\text { Total amount of } \\
\text { acidity }^{\mathbf{b}}(\mathbf{\mu m o l} / \mathbf{g})\end{array}$ & $\begin{array}{c}\text { Crystallite } \\
\text { size }^{\mathbf{c}}(\mathbf{n m})\end{array}$ \\
\hline $\mathrm{LaP}(2.0)[500]$ & 1.89 & 321.7 & 7.9 \\
$\mathrm{LaP}(1.0)[500]$ & 0.95 & 369.3 & 8.5 \\
$\mathrm{LaP}(0.5)[500]$ & 0.58 & 409.7 & 8.6 \\
$\mathrm{LaP}(0.35)[500]$ & 0.41 & 494.9 & 9.8 \\
$\mathrm{LaP}(0.2)[500]$ & 0.25 & 576.7 & 10.4 \\
$\mathrm{LaP}(0.35)[\mathrm{UC}]$ & 0.44 & 728.6 & 8.4 \\
$\mathrm{LaP}(0.35)[400]$ & 0.41 & 595.5 & 9.2 \\
$\mathrm{LaP}(0.35)[600]$ & 0.32 & 375.7 & 13.2 \\
$\mathrm{LaP}(0.35)[800]$ & 0.28 & 196.6 & 17.8 \\
$\mathrm{LaP}(0.35)[500$ used] & 0.45 & 481.4 & - \\
\hline
\end{tabular}

a) Determined from EDS results,

b) Determined from NH3-TPD analysis

c) Calculated from XRD results

The XRD patterns of LaP catalysts are shown in Figure 2. All the samples are showing similar diffraction patterns and the diffraction patterns indicates the rhabdophane lanthanum phosphate crystalline structure (JCPDS file no. 46-1439). The phase transformation from rhabdophane to monoclinic lanthanum phosphate (JCPDS file no. 35-0731) was observed for the $\mathrm{LaP}(0.35)[\mathrm{T}]$ sample that are calcined at 600 and $800{ }^{\circ} \mathrm{C}$ [45]. The shape of the diffraction peaks in the XRD pattern suggests that the samples are highly crystalline and well ordered. However, the LaP catalysts calcined at $800{ }^{\circ} \mathrm{C}$ shown better crystallinity with larger crystallite size as 
indicated by the sharp and intense XRD peaks [46]. The crystallite sizes of the LaP-based catalysts are calculated by using Scherrer's equation (Table 1).
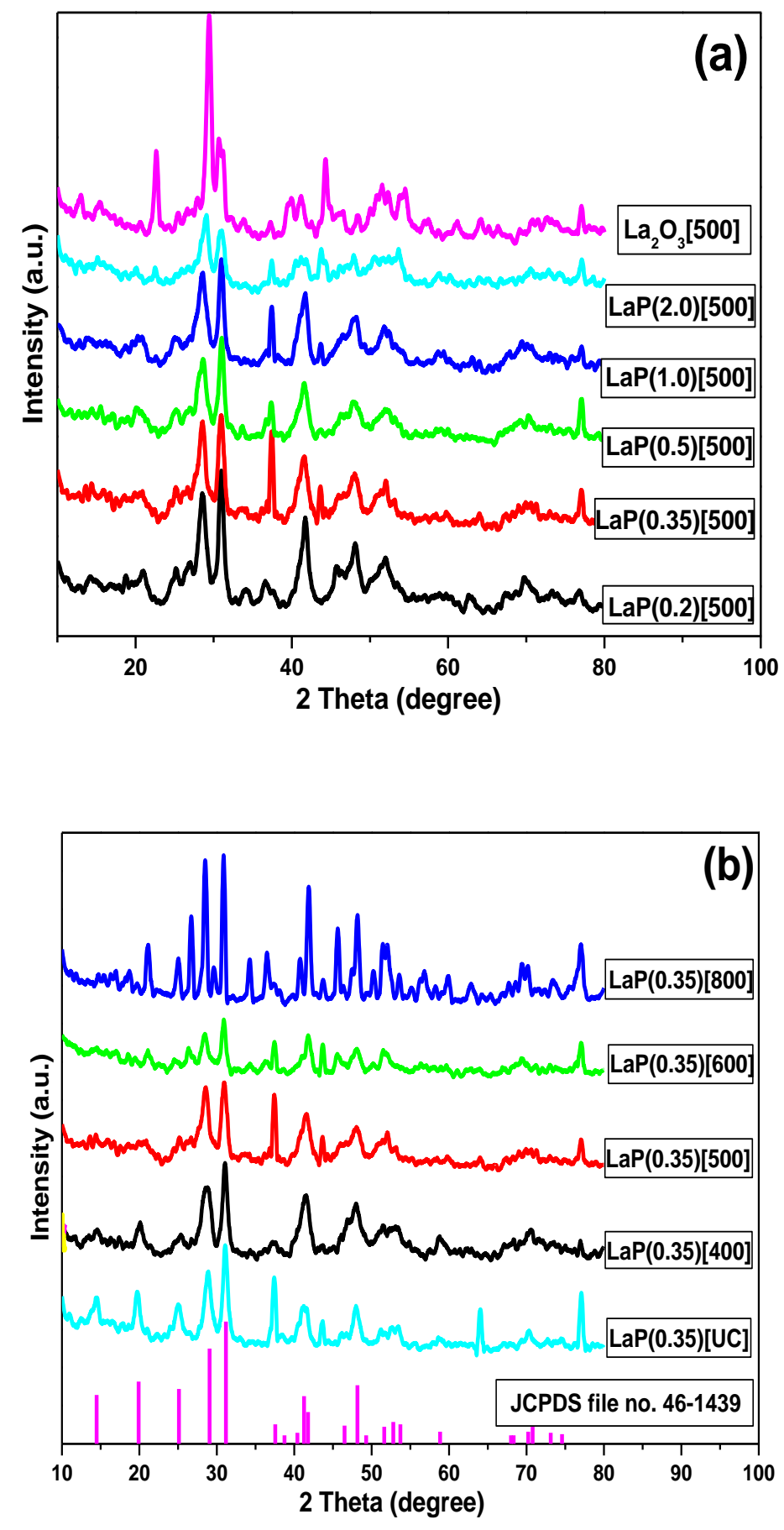
Figure 2. XRD patterns of a) $\mathrm{LaP}(\mathrm{m})[500]$ samples and b) $\mathrm{LaP}(0.35)[\mathrm{T}]$ samples (where $\mathrm{m}=$ mole ratios, $\mathrm{T}=$ calcination temperature) .

The crystallite size increased gradually with the phosphate amount and the calcination temperature for the $\mathrm{LaP}(\mathrm{m})[500]$ and $\mathrm{LaP}(0.35)[\mathrm{T}]$ catalysts. The $\mathrm{LaP}(0.35)[600]$ and $\mathrm{LaP}(0.35)[800]$ catalysts shown the large crystallite sizes of $13.2 \mathrm{~nm}$ and $17.8 \mathrm{~nm}$, respectively. Whereas, at low La/P ratio and at low calcination temperature, the sample exhibited smaller crystallite size.

The FT-IR spectra of all LaP catalysts are presented in Figure 3. The broad band in the region $3300-3600 \mathrm{~cm}^{-1}$ for $\mathrm{LaP}$ samples are attributed to $\mathrm{OH}$ stretching vibrations of the residual water and structural hydroxyl (-OH) groups. In addition, the corresponding bending vibration was observed at $1635 \mathrm{~cm}^{-1}$. The intensity of these IR bands declined with lowering the phosphate amount from $\mathrm{LaP}(0.35)[500]$ to $\mathrm{LaP}(2.0)[500]$ and, completely diminished for the pure $\mathrm{La}_{2} \mathrm{O}_{3}$ sample (Figure 3a). This phenomenon is also observed with the samples $\mathrm{LaP}(0.35)[\mathrm{T}]$, which are calcined from 400 to $800{ }^{\circ} \mathrm{C}$. While the predominant peaks between $940-1150 \mathrm{~cm}^{-1}$ are attributed to phosphate P-O stretching, the peaks around 619 and $538 \mathrm{~cm}^{-1}$ corresponds to the O$\mathrm{P}=\mathrm{O}$ bending and $\mathrm{O}-\mathrm{P}-\mathrm{O}$ bending vibrations, respectively. The $\mathrm{P}-\mathrm{O}$ IR stretching band appears to be broad and single for the LaP samples which are calcined at 400 and $500{ }^{\circ} \mathrm{C}$. However, the IR band splitted into two bands for the samples calcined above $500{ }^{\circ} \mathrm{C}$, this indicates the formation of monoclinic lanthanum phosphate phase $[45,47]$. The initiation of the monoclinic phase formation above $600{ }^{\circ} \mathrm{C}$ is also evident from the $\mathrm{X}$-ray diffraction analysis (Figure $2 \mathrm{~b}$ ). 

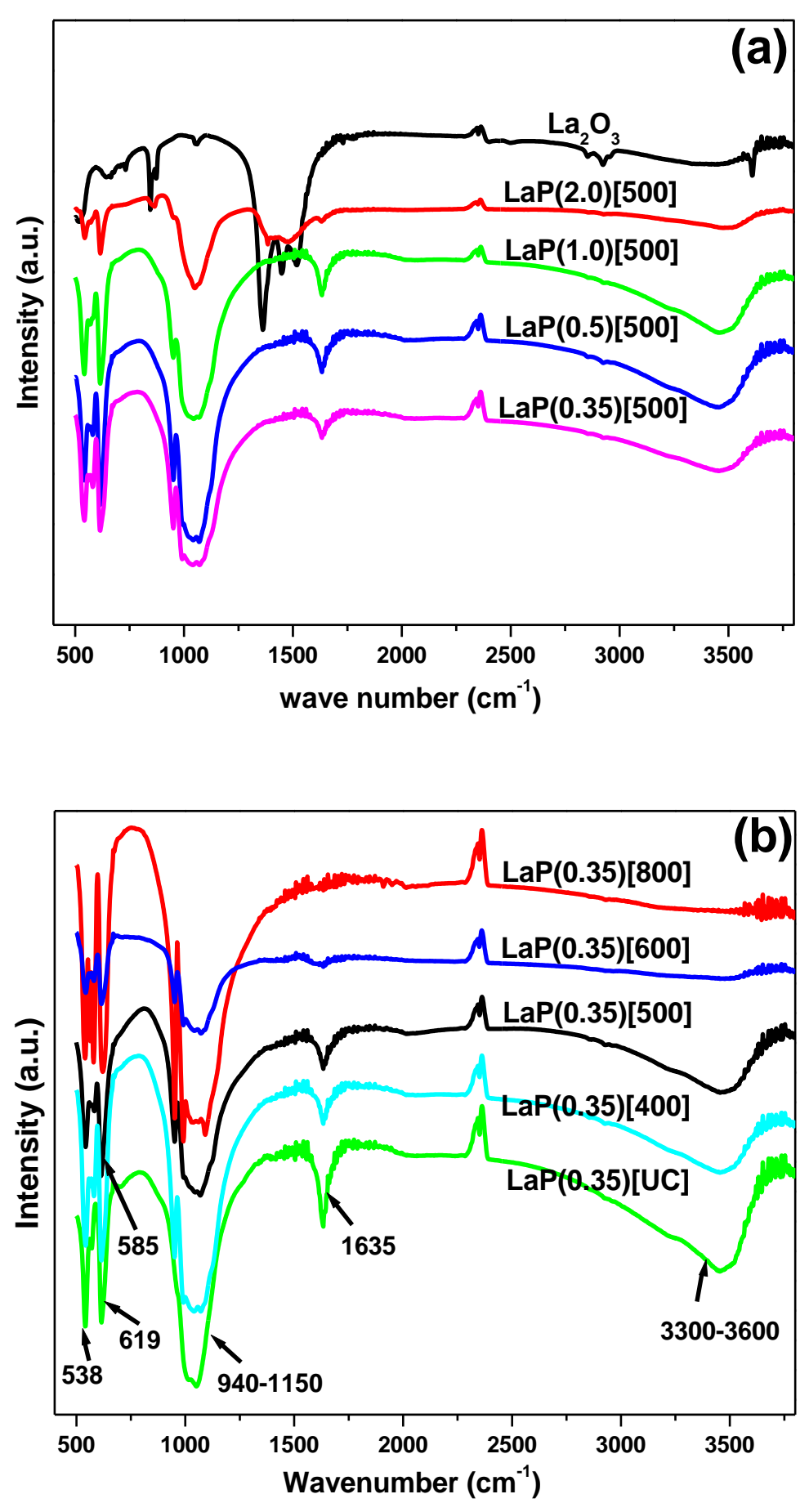

Figure 3. FT-IR spectra of a) $\mathrm{LaP}(\mathrm{m})[500]$ and b) $\mathrm{LaP}(0.35)[\mathrm{T}]$ catalysts. 

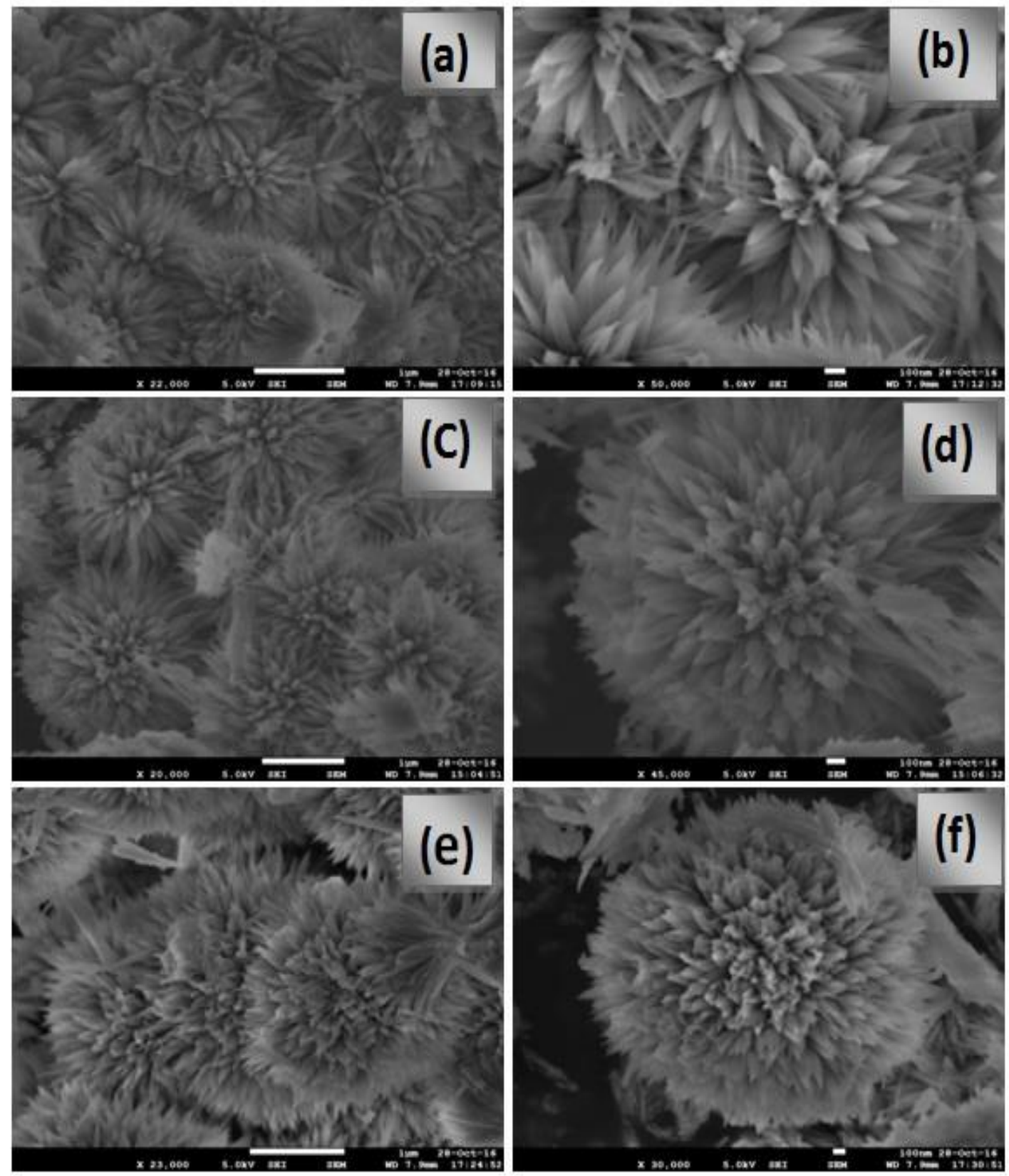

Figure 4. SEM images with different magnifications of LaP(0.35)[500]- a) $1 \mu \mathrm{m} \mathrm{b}) 100 \mathrm{~nm}$, $\operatorname{LaP}(0.35)[\mathrm{UC}]-\mathrm{c}) 1 \mu \mathrm{m} \mathrm{d}) 100 \mathrm{~nm}$ and spent LaP(0.35)[500]- e) $1 \mu \mathrm{m} \mathrm{f)} 100 \mathrm{~nm}$

The Figure 4 represents the SEM images of $\operatorname{LaP}(0.35)[500], \operatorname{LaP}(0.35)[\mathrm{UC}]$ and spent $\mathrm{LaP}(0.35)[500]$ catalysts with different magnifications, suggesting that all the LaP catalysts have 
a dandelion-like structure without distorting any structure before and after calcination and after reaction. Thus, indicates structure is stable and intact without any phase changes even after repeated thermal cycles. Similar results were reported previously for the lanthanum phosphatebased nano structures [48].

The $\mathrm{NH}_{3}$-TPD profiles of $\mathrm{LaP}(\mathrm{m})[500]$ and $\mathrm{LaP}(0.35)[\mathrm{T}]$ catalysts were shown in Figure 5. All the peaks observed in Figure $5 \mathrm{a}$ and $5 \mathrm{~b}$ are in the temperature range $100-200{ }^{\circ} \mathrm{C}$, thus, $\mathrm{LaP}$ catalysts exhibits mainly the weak acid sites. As the amount of phosphate increases from $\mathrm{LaP}(2.0)[500]$ to $\mathrm{LaP}(0.35)[500]$ the amount of total acidity increased. Moreover, $\mathrm{LaP}(0.2)[500]$ catalyst having the highest phosphate amount among all the catalysts; henceforth, this catalyst also possess moderate and strong acid sites in addition to the weak acid sites. Further, the amount of total acidity decreased with the calcination temperature (see Table 1). This was attributed to the structural and phase changes occurred during calcination. 

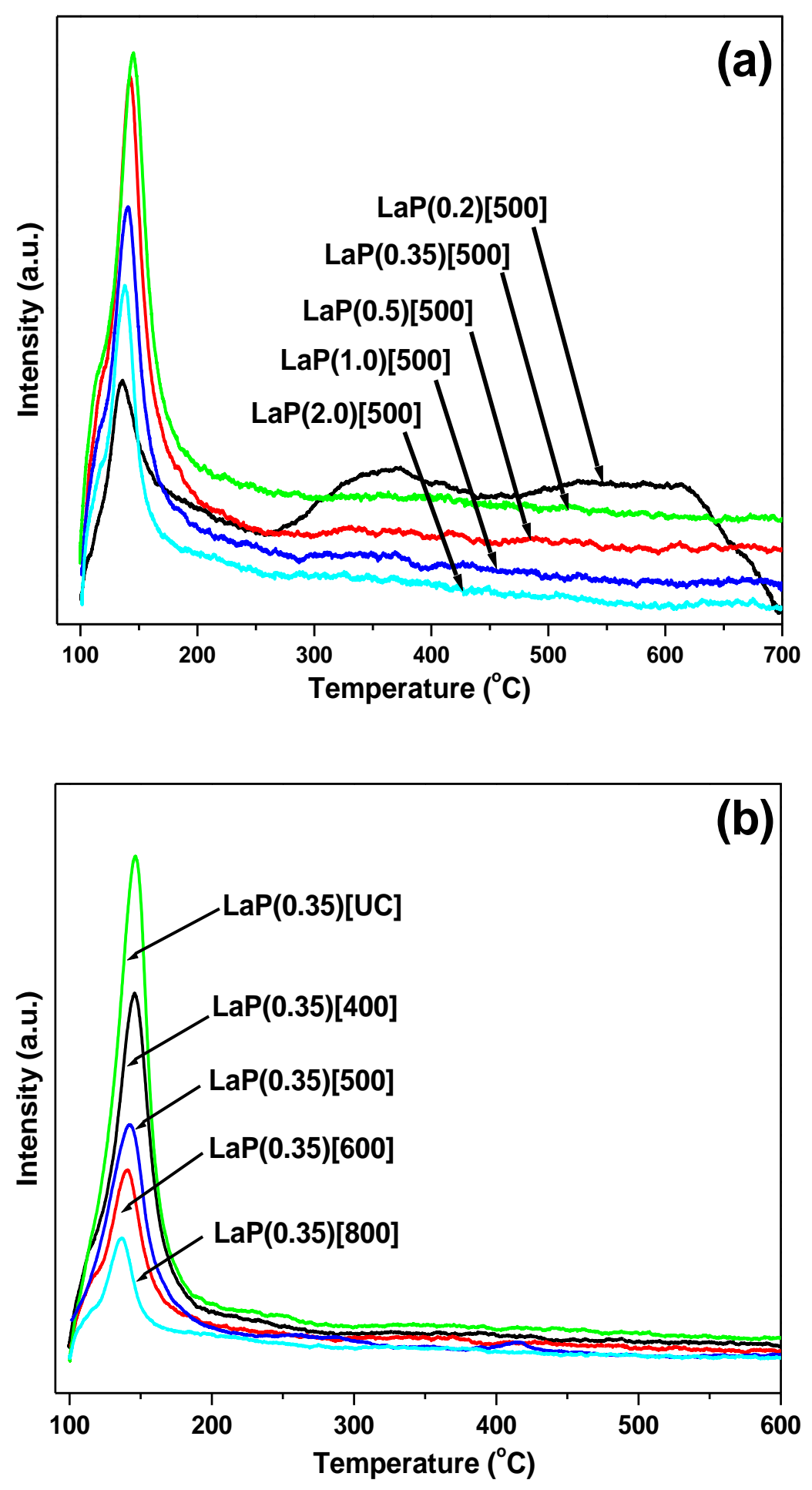

Figure 5: $\mathrm{NH}_{3}$-TPD profiles for a) $\mathrm{LaP}(\mathrm{m})[500]$ and b) LaP(0.35)[T] catalysts. 


\subsection{Catalytic activity}

All the prepared catalysts with different mole ratios $\mathrm{LaP}(\mathrm{m})[500]$ and calcined $\mathrm{LaP}(0.35)[\mathrm{T}]$ catalysts are tested in LA dehydration reaction in a fixed bed reactor under atmospheric pressure. The catalyst $\mathrm{LaP}$ with 0.35 ratio (calcined at $500^{\circ} \mathrm{C}$ ) found to be most active and selective catalyst and also achieved highest AA yield compared to all catalysts. The $\mathrm{LaP}(0.35)[500]$ catalyst possess optimal amount of weak acid sites, probably which are Lewis acidity from P-O bonding and responsible for the superior performance in LA dehydration. Typically, LaP-based catalysts exhibits high Lewis acidity than Bronsted acidity with low basicity [41]. At high La/P ratios, basicity of the samples increases due to increased surface La$\mathrm{OH}$ sites. Moreover, basicity has minimal or no role in catalyzing LA to AA as reported in [41]. Further tests conducted to find the most optimized conditions by changing the reaction parameters over the $\mathrm{LaP}(0.35)[500]$ catalyst i.e. reaction temperature, feed flow rate (WHSV) and feed concentrations.

\section{Effect of La/P mole ratio}

The effect of $\mathrm{La} / \mathrm{P}$ ratio is an important parameter to optimize and to design a superior catalyst for LA dehydration. The LaP catalyst with 0.35 ratio found to be the most active and selective compared to all tested catalysts. The weak acid sites played an important role in catalyzing the LA to AA and LaP catalyst with 0.35 ratio possess moderately high and optimal amount of acidity, thus exhibited high conversion and selectivity. Initially for 1-2 h, complete LA conversion was achieved and showed a stable trend for the LaP catalyst which is calcined at $500^{\circ} \mathrm{C}$. The significant decrease in conversion was observed with time on stream except for $\mathrm{LaP}(0.35)[500]$ and $\mathrm{LaP}(0.2)[500]$ catalysts. The maximum AA selectivity (> 70\%) was 
achieved over the $\mathrm{LaP}(0.35)$ [500] catalyst but the selectivity declined with mole ratio. The lowest AA selectivity was observed for the catalysts $\mathrm{LaP}(1.0)[500]$ and $\mathrm{LaP}(2.0)[500]$ compared to all the tested LaP catalysts due to low surface acidity. Henceforth, by varying the La/P ratio can acidity significantly affect the conversion and selectivity due to the changes in the total acidity and the strength. From the literature, it is well known that the catalytic performance of the LA dehydration into AA is mainly depend on the acid-base and redox properties. It is clearly evident that the AA selectivity increased with the phosphate content (i.e. up to La/P ratio of 0.35) and then starts to decrease. The phosphate bonding in LaP catalysts creates weak acid sites with lanthanum. Thus, optimal amount of phosphate i.e. La/P ratio of 0.35 exhibited moderately high amount of acidity, which are predominantly weak acid sites corresponds to $100-150^{\circ} \mathrm{C}$. Henceforth, the acidity strength of the catalysts played a key role in determining the AA selectivity. However, the samples with low La/P mole ratio (LaP-0.2) possesses highest acidity, but exhibited low AA selectivity. This phenomenon could be explained by the presence of medium and strong acidic sites in the LaP-0.2 sample, which are more favorable in decarbonylation than dehydration mechanism. As a result, the acetaldehyde selectivity found to be the highest for the catalyst LaP-0.2 sample. As mentioned earlier, all the LaP catalysts exhibited highest activity in terms of conversion in the initial hour, the samples with high phosphate content (LaP-0.2 and LaP-0.35) shown stable trend with time on stream. From this result, it is evident that the LA conversion and AA selectivity mainly depends on the total acidity and acidity strength of the catalysts [31]. Hence, the best and optimal ratio of La/P $=0.35$ was found to be the most appropriate in gaining the best performance in terms of highest LA conversion, AA selectivity and AA yield due to balanced acidity profile. 

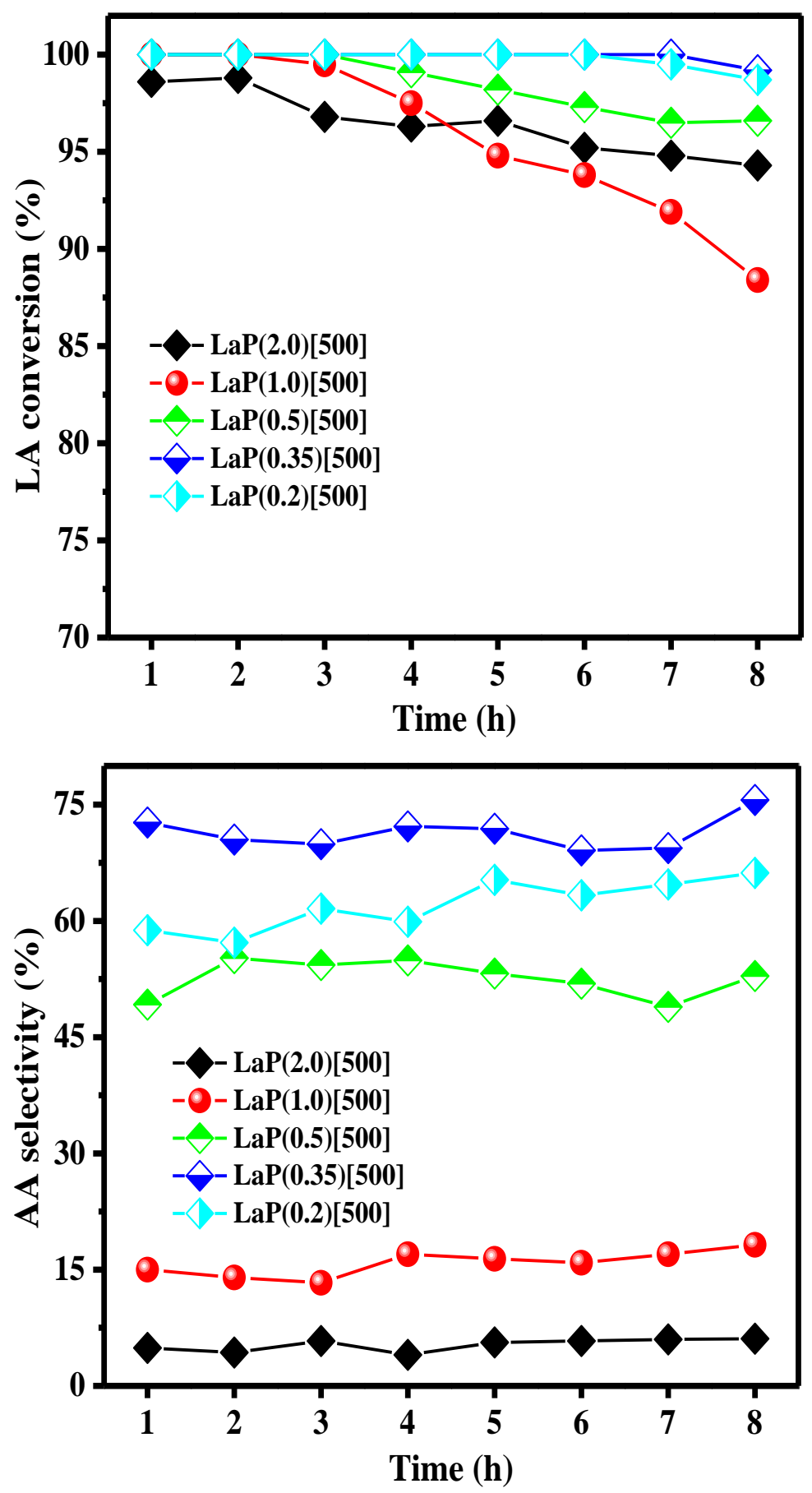
Figure 6. Effect of La/P mole ratio for different LaP(m)[500] samples for LA dehydration. Reaction conditions: LA concentration $=30 \mathrm{wt} \%$, feed flow $=1.5 \mathrm{~mL} / \mathrm{h}$, carrier gas $\left(\mathrm{N}_{2}\right)$ $=30 \mathrm{~mL} / \mathrm{min}$, reaction temperature $=360^{\circ} \mathrm{C}, \mathrm{WHSV}=3.156 \mathrm{~h}^{-1}$ and catalyst amount $=500 \mathrm{mg}$.

\section{Effect of calcination temperature}

The influence of different calcination temperatures (T) was studied with LaP (0.35)[T] catalysts (where $\mathrm{T}=400-800{ }^{\circ} \mathrm{C}$ ) on LA conversion, AA selectivity and AA yield, respectively (Figure 7). The catalysts $\operatorname{LaP}(0.35)[400]$ and $\operatorname{LaP}(0.35)[500]$ showed complete conversion ( 100 $\%$ ) with different AA selectivity values. Over $\operatorname{LaP}(0.35)[500]$, a maximum selectivity of $\sim 74 \%$ was achieved compared to all catalysts. Even though the $\mathrm{LaP}(0.35)[400]$ possess highest acidity than $\operatorname{LaP}(0.35)[500]$ but exhibited slightly lower selectivity. The low selectivity is due to the undesirable decarboxylation/decarbonylation of LA to acetaldehyde side reactions. While the $\mathrm{LaP}(0.35)[\mathrm{T}]$ calcined at 600 and $800{ }^{\circ} \mathrm{C}$ shown lower LA conversion and AA selectivity due to low acidity. This result suggests that, acidity not only favors the dehydration but also active in the decarbonylation/decarboxylation side reactions. 

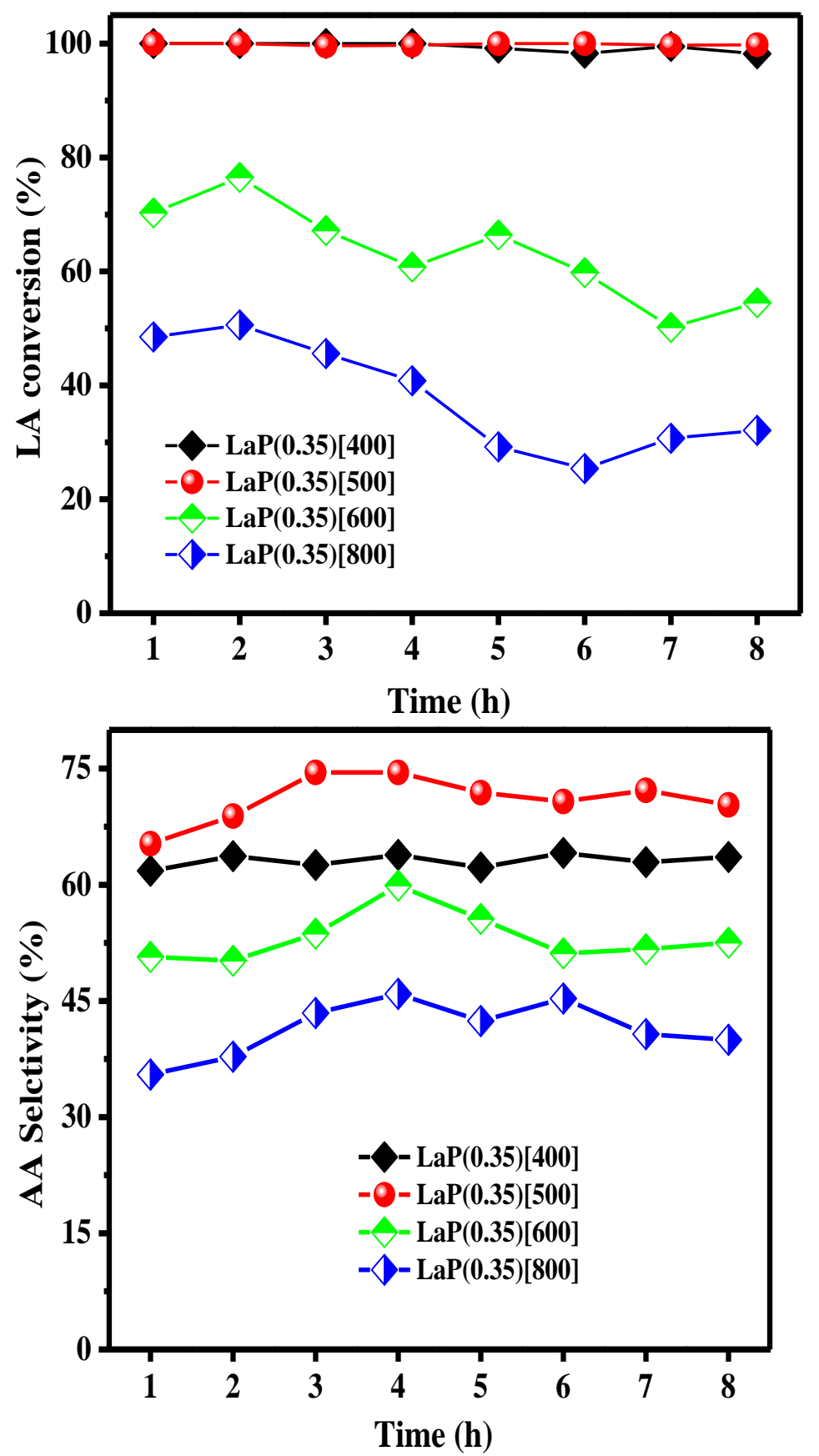

Figure 7. Effect of calcination temperatures for different $\mathrm{LaP}(0.35)[\mathrm{T}]$. Reaction conditions: LA concentration $=30 \mathrm{wt} . \%$, feed flow $=1.5 \mathrm{~mL} / \mathrm{h}$, carrier gas $\left(\mathrm{N}_{2}\right)=30 \mathrm{~mL} / \mathrm{min}$, reaction temperature $=360{ }^{\circ} \mathrm{C}, \mathrm{WHSV}=3.156 \mathrm{~h}^{-1}$ and catalyst amount $=500 \mathrm{mg}$. 


\section{Effect of reaction temperature}

The influence of reaction temperature on LA conversion and AA selectivity was tested in the temperature range $300-420{ }^{\circ} \mathrm{C}$ and the results were showed in Figure 8. As predicted, temperature had profound effect on conversion and products formation. The LA conversion increased with temperature and reached complete conversion at $360^{\circ} \mathrm{C}$, and then conversion maintained stable and constant till $420^{\circ} \mathrm{C}$.However, selectivity trend had significant effect due to temperature. Initially, AA selectivity increases with temperature up to $360^{\circ} \mathrm{C}$, and thereafter drops to below $30 \%$ at $400^{\circ} \mathrm{C}$. At higher temperatures, side reactions and byproducts formation rate are favorable compared to desired AA production.

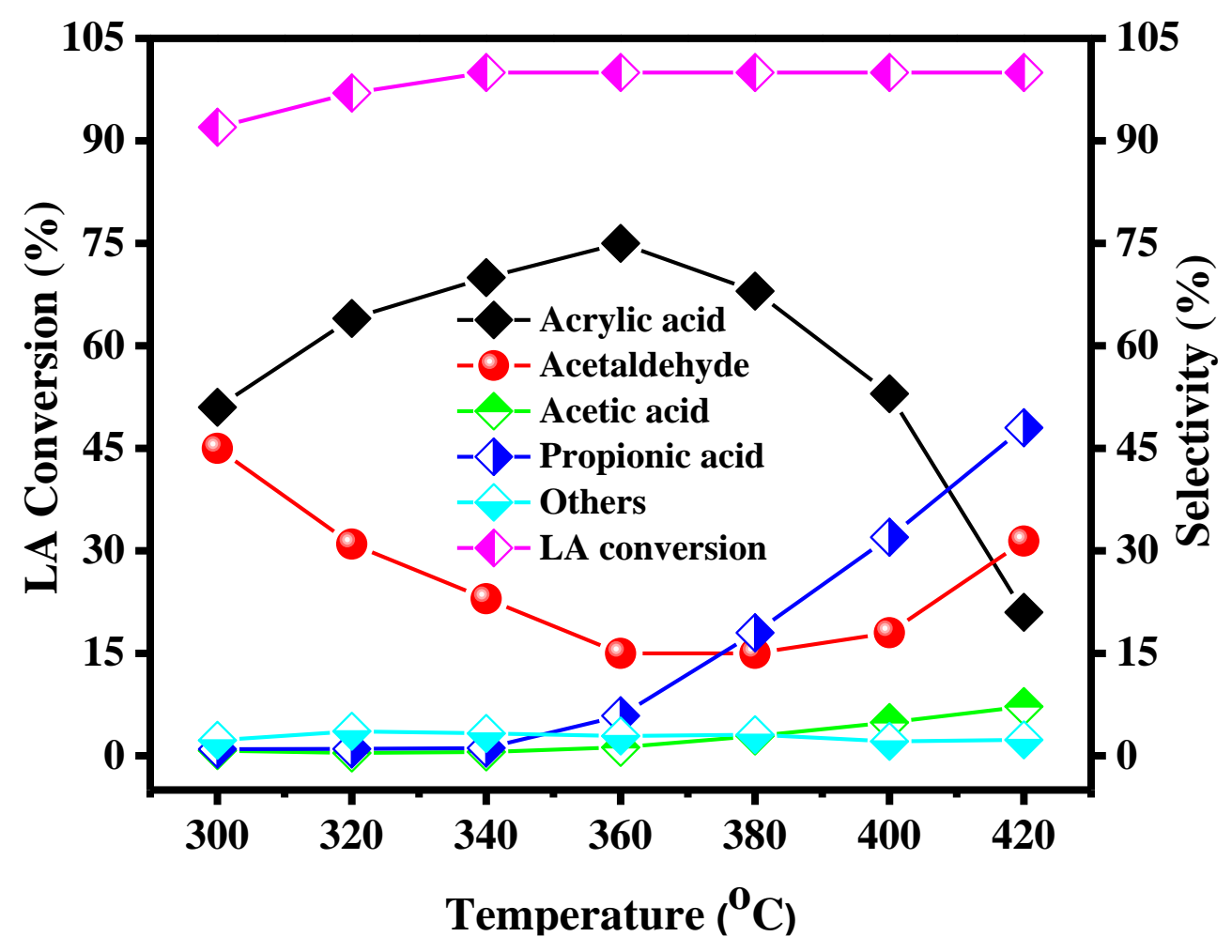

Figure 8: Effect of reaction temperature on LTA reaction over LaP(0.35)[500]. 
Reaction conditions: reaction feed $=30 \mathrm{wt} \%$ LA, feed flow rate $=1.5 \mathrm{~mL} /$, carrier gas $\left(N_{2}\right)=$ $30 \mathrm{~mL} / \mathrm{min}$, catalyst LaP(0.35)[500] $=500 \mathrm{mg}$ and $\mathrm{WHSV}=3.156 \mathrm{~h}^{-1}$. Others includes 2,3pentane-dione, hydroxy acetone and some other unidentified products.

Whereas, the reaction temperature had a profound effect on AA selectivity, and it shown a volcano type curve to reach a maximum selectivity of $74 \%$ at $360^{\circ} \mathrm{C}$. The major byproduct i.e. acetaldehyde was produced in higher amounts at lower temperature i.e. below $360^{\circ} \mathrm{C}$. While other byproduct i.e. propionic acid exhibited low selectivity (below $360^{\circ} \mathrm{C}$ ) and thereafter, acetaldehyde and propionic acid starts to increase and reach maximum at higher temperatures (around $420^{\circ} \mathrm{C}$ ).

\section{Effect of feed flow rates}

The effect of feed flow rate i.e. weight hourly space velocity (WHSV) was investigated by using different lactic acid $(30 \mathrm{wt} . \%)$ flowrates ranging from $0.5 \mathrm{~mL} / \mathrm{h}$ to $2.0 \mathrm{~mL} / \mathrm{h}$ flow rates were studied . A complete LA conversion was achieved until $1.5 \mathrm{~mL} / \mathrm{h}$ feed flow rate and thereafter conversion decreases steadily due to short reactant residence time. At high flow rates, LA amount will be in higher concentrations compared to the active sites and also shorter reaction times. Further AA selectivity of above $\sim 80 \%$ at $0.5 \mathrm{~mL} / \mathrm{h}$ flow rate was achieved, and thereafter, selectivity slightly drops to $70 \%$ at $2.0 \mathrm{~mL} / \mathrm{h}$. Overall, a consistent and stable LA conversion was gained for all the flow rates. However, the selectivity fluctuated over the time on stream and a maximum of $75 \%$ selectivity was achieved at $0.5 \mathrm{~mL} / \mathrm{h}$ due to disproportionation side reactions. 


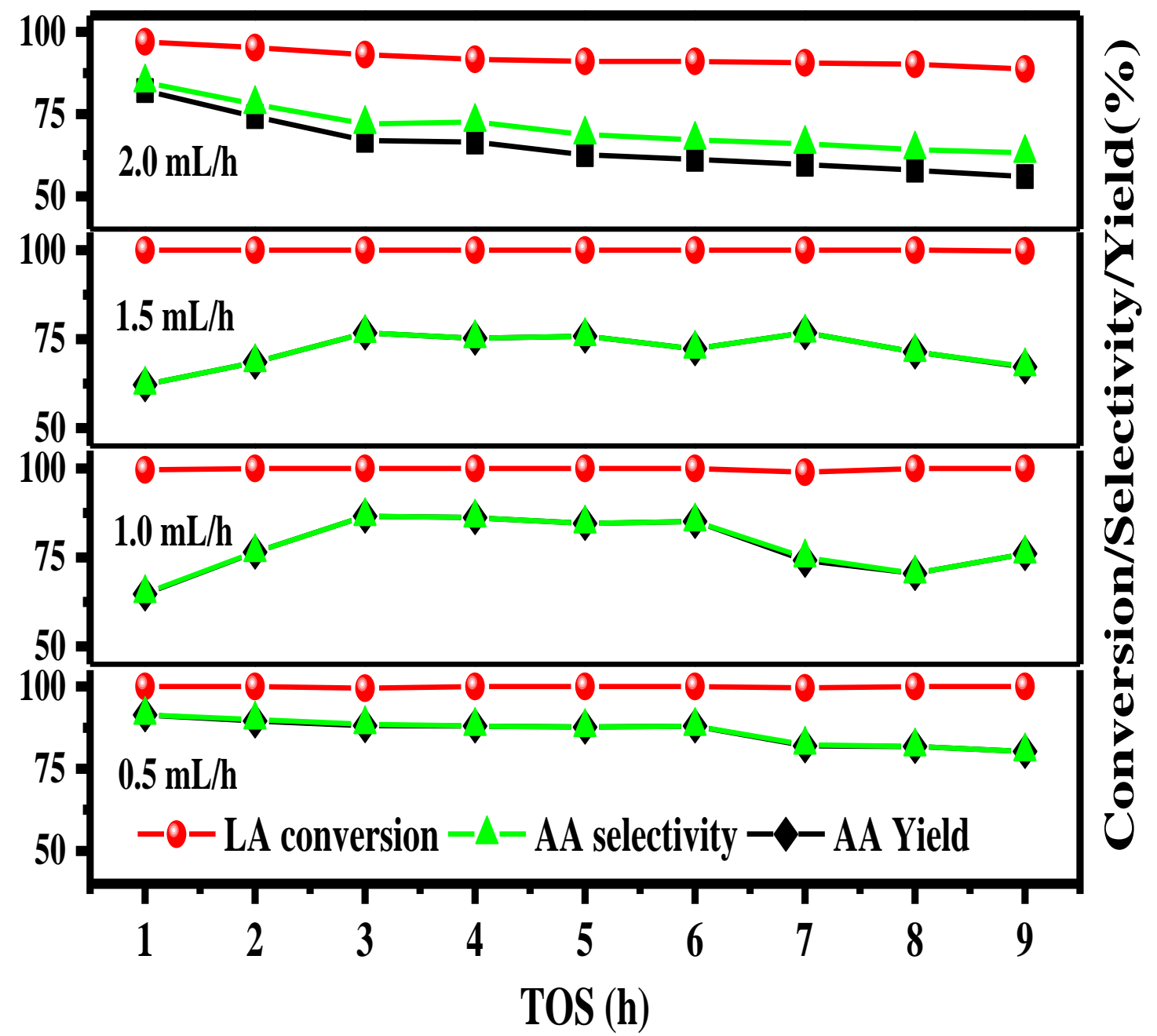

Figure 9: Effect of feed flow rates ( $m L / h)$ : LA conversion () AA selectivity ( $\Delta)$ and AA yield (ם). Reaction conditions: Reaction feed $=30 \mathrm{wt} \% \mathrm{LA}$, carrier gas $\left(N_{2}\right)=30 \mathrm{~mL} / \mathrm{min}$, reaction temperature $=360^{\circ} \mathrm{C}$ and catalyst LaP(0.35) $[500]=500 \mathrm{mg}$.

\section{Effect of LA concentration}

Different lactic acid concentrations were studied and found that the concentration had significant effect on the conversion and selectivity. e A complete LA conversion was achived between 1030wt.\% concentrations and no effect was found. However, at 40 wt.\% LA concentration, the conversion gradually drops with time on stream. However, the selectivity varied between 70 to 
$75 \%$ for 10, 20 and $30 \mathrm{wt} \%$ LA concentrations, respectively. As higher the LA concentration, WHSV would be higher according to the given formula. Therefore $30 \mathrm{wt} \%$ aqueous LA was used as optimized concentration for $1.5 \mathrm{~mL} / \mathrm{h}$ feed flow.

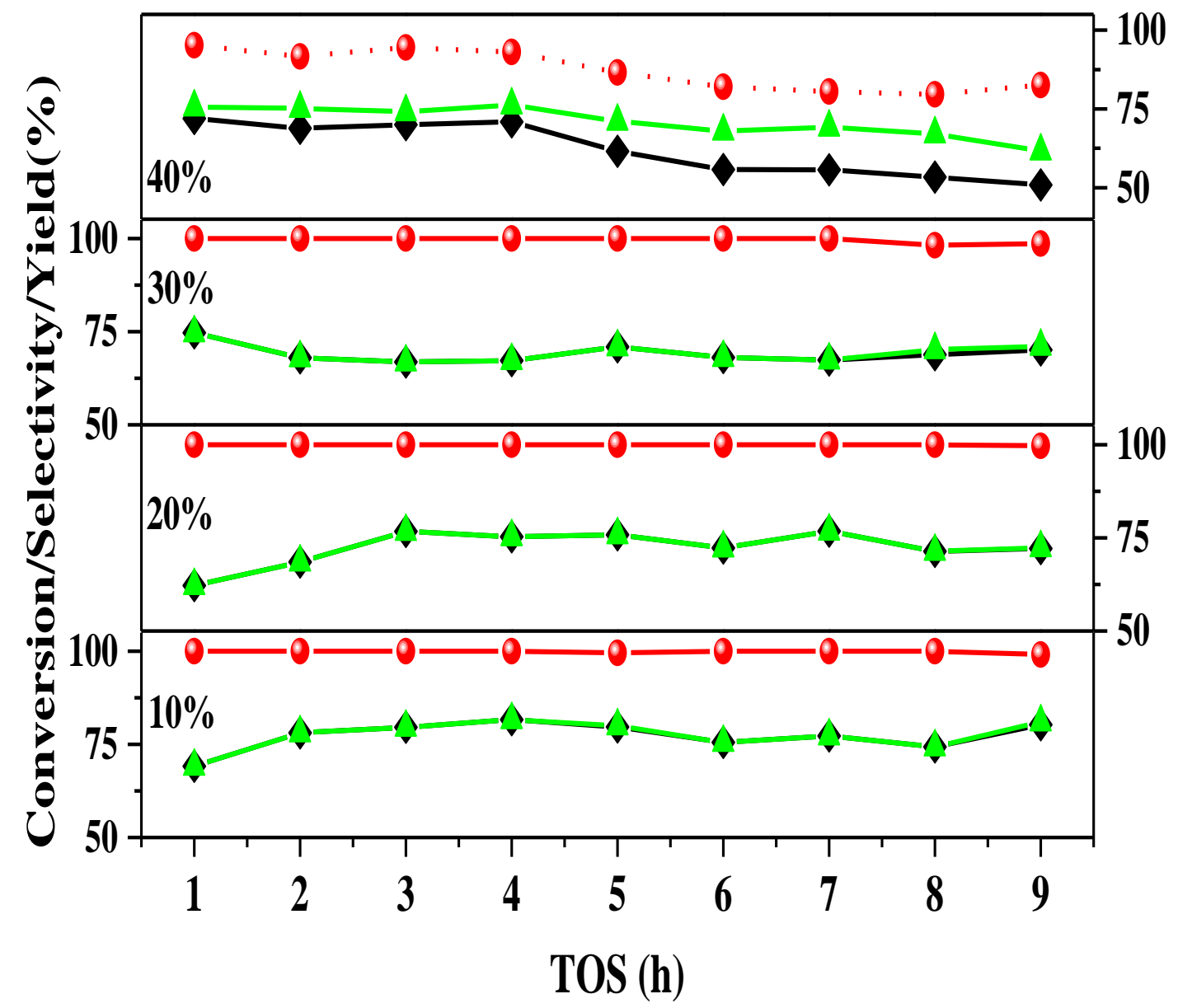

Figure 10: Effect of LA concentration (wt\%): LA conversion (०) AA selectivity ( $\Delta$ ) and AA yield (a).

Reaction conditions: $L A$ feed flow $=1.5 \mathrm{~mL} / \mathrm{h}$, carrier gas $\left(N_{2}\right)=30 \mathrm{~mL} / \mathrm{min}$, reaction temperature $=360^{\circ} \mathrm{C}, \mathrm{WHSV}=3.156 \mathrm{~h}^{-1}$ and catalyst LaP $(0.35)[500]=500 \mathrm{mg}$. 
Time on stream (TOS) studies was carried out using LaP(0.35)[500] in an optimized reaction condition. The catalyst was tested for three different thermal cycles without removing from the catalyst bed. In addition, the catalyst was regenerated between each cycle by treating the catalyst bed with air flow $(50 \mathrm{~mL} / \mathrm{min})$ at $450{ }^{\circ} \mathrm{C}$ for $6-8 \mathrm{~h}$ in order to remove the coke deposition over the active phase. In the first cycle, a consistent and stable conversion was observed for up to $15 \mathrm{~h}$ TOS, and afterward, conversion drops to $80 \%$ until $24 \mathrm{~h}$ TOS. In the second cycle, a similar trend was observed, starts with complete conversion, and gradually declined after $8 \mathrm{~h}$ TOS and reached $80 \%$ at $18 \mathrm{~h}$. In the final cycle, starts with complete conversion and rapidly drops to $80 \%$ conversion at $12 \mathrm{~h}$ TOS. The AA selectivity trend for three cycles found to be similar and the selectivity varied between $70-80 \%$. 


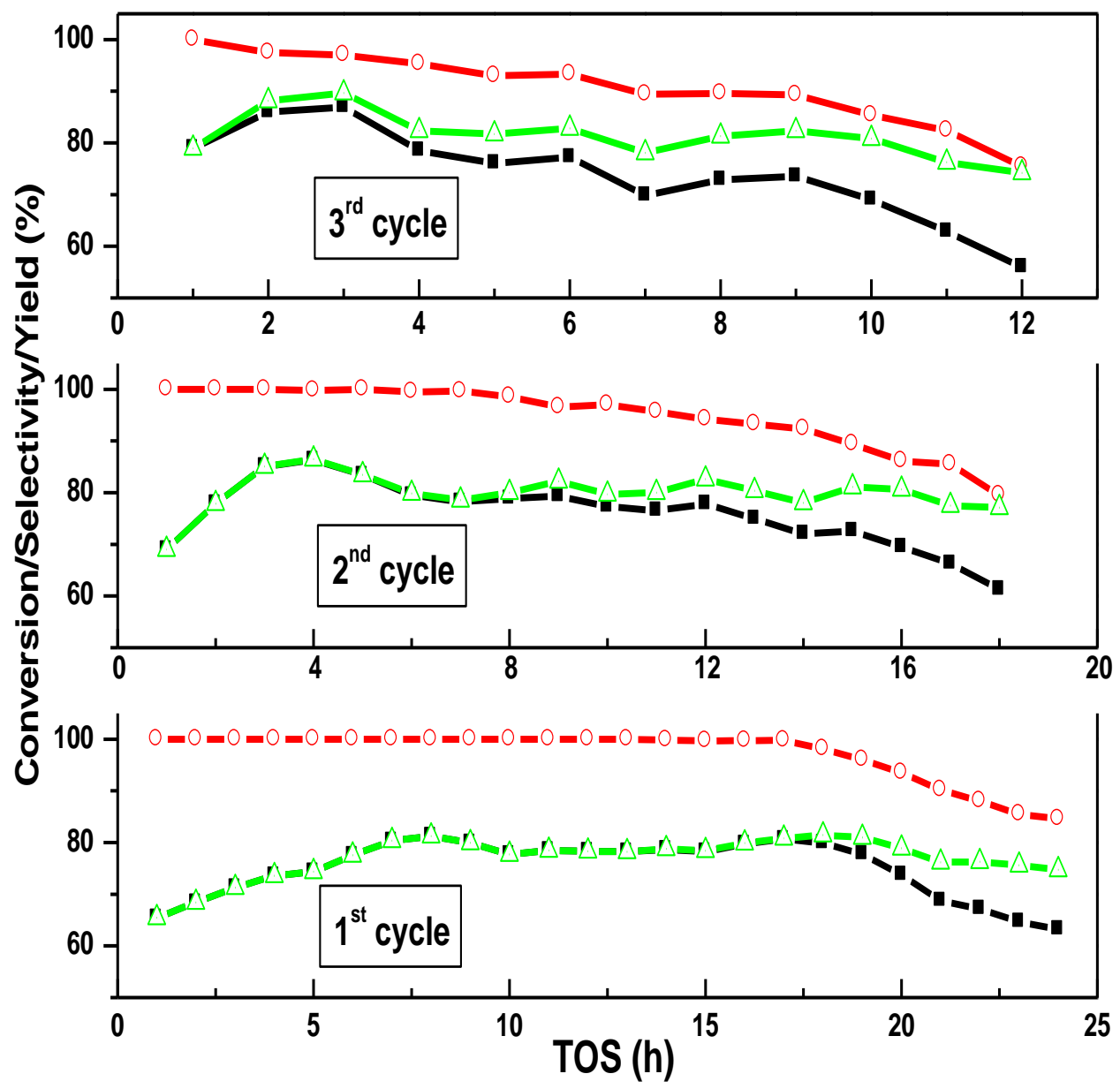

Figure 11: Time on stream for three cycles: LA conversion (०) AA selectivity ( $\Delta$ ) and AA yield (घ). Reaction conditions: LA concentration $=30 \mathrm{wt} . \%$, feed flow $=1.5 \mathrm{~mL} / \mathrm{h}$, carrier gas $\left(\mathrm{N}_{2}\right)=$ $30 \mathrm{~mL} / \mathrm{min}$, reaction temperature $=360^{\circ} \mathrm{C}, \mathrm{WHSV}=3.156 \mathrm{~h}^{-1}$ and catalyst LaP(0.35) [500] $=$ $500 \mathrm{mg}$

\subsection{Deactivation studies}

The deactivation studies on $\mathrm{LaP}(0.35)[500]$ catalyst was performed at different stages of catalytic studies. The deactivation phenomena was thoroughly investigated before and after calcination and after reaction (used catalyst). From XRD (Figure 12), FT-IR (Figure 13) and SEM (Figure 14) analysis was performed and it was confirmed that there are phase and structural 
changes have been found for the used catalyst (after reaction). From TGA analysis of the used catalysts exhibited a weight loss peak occurred between $300-450{ }^{\circ} \mathrm{C}$ due to deactivation (Figure 14). This weight loss of the catalyst might be due to the carbon gasification over the catalysts as $\mathrm{CO}_{2}$. The XRD measurements detected no signal for the carbon deposits on the $\mathrm{LaP}(0.35)[500]$ used catalysts (Figure 12), thus confirmed that the formed carbon deposited was presented in the amorphous form. The elemental CHNS analysis also confirmed the presence of carbon formation on the used catalysts (Table 2). The measured $\mathrm{H} / \mathrm{C}$ ratio on the surface and the bulk of the used catalyst $\mathrm{LaP}(0.35)[500$ used $]$ was found to be lower $(\mathrm{H} / \mathrm{C}=0.064)$, which indicates that the formed surface carbon deposits probably presented in the considerable range and much higher on the surface. The Figure 12 represents the $\mathrm{NH}_{3}$-TPD of $\mathrm{LaP}(0.35)[500]$ for calcined and used catalysts.

Table 2. CHNS analysis for the used and calcined catalysts.

\begin{tabular}{cccccc}
\hline Catalyst & $\mathbf{C \%}$ & $\mathbf{H \%}$ & $\mathbf{N \%}$ & $\mathbf{S \%}$ & H/C ratio \\
\hline LaP(0.35) [Calcined] & 0.11 & 0.32 & 0.00 & 0.00 & 2.91 \\
& & & & & \\
$\operatorname{LaP}(0.35)[$ Used] & 4.07 & 0.26 & 0.00 & 0.00 & 0.064 \\
\hline
\end{tabular}

The total surface acidity values for $\mathrm{LaP}(0.35)$ [Calcined] and $\mathrm{LaP}(0.35)$ [Used] (Table 3.2.1) are quite similar. From Figure 15 it was clearly observed that the weak acidic sites of $\mathrm{LaP}(0.35)[$ Used] was decreased. Hence, the additional amount of acidity was given by the peak observed in the moderate acidity range between $300-400{ }^{\circ} \mathrm{C}$, which is attributed to the acidity of 
surface adsorbed carbon deposits [49]. Thus, this will affect the conversion and selectivity of the used catalyst.

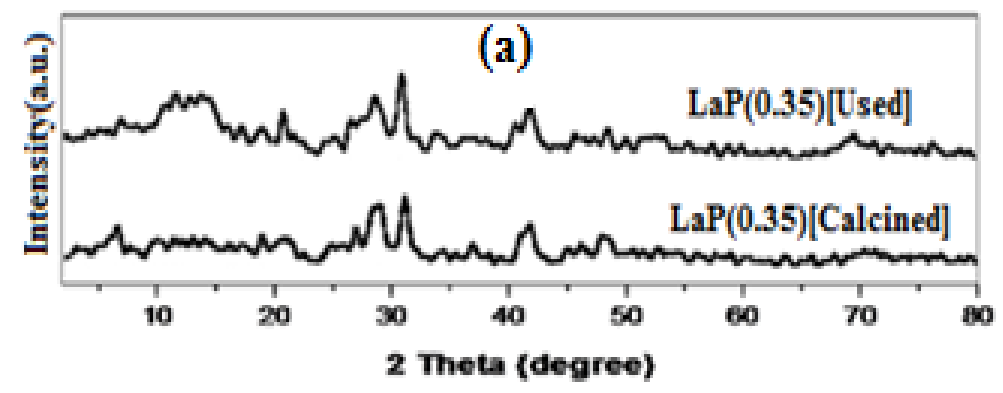

Figure 12: XRD patterns for calcined and used LaP(0.35)[500]catalysts.

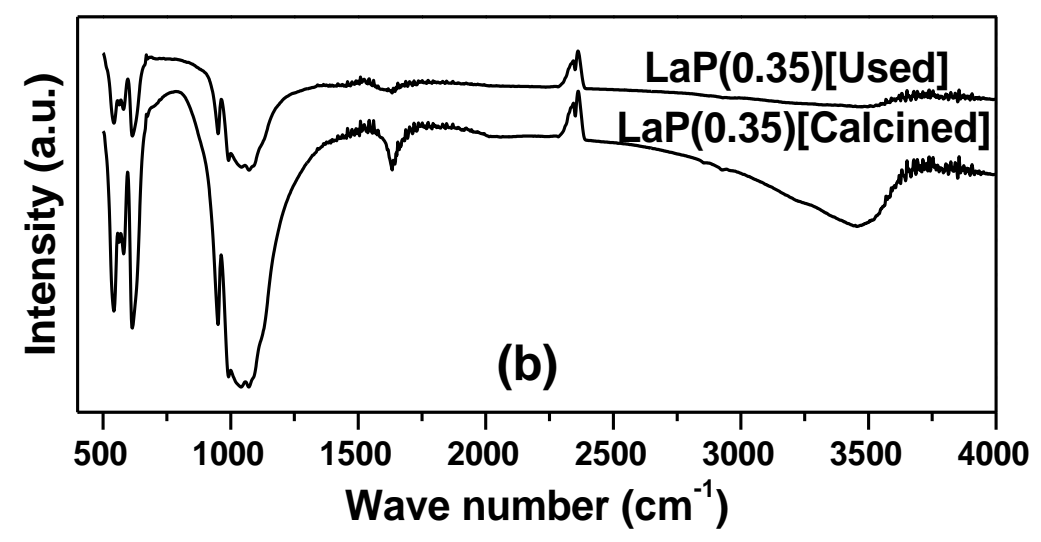

Figure 13: FT-IR spectra for calcined and used LaP(0.35)[500] catalysts. 


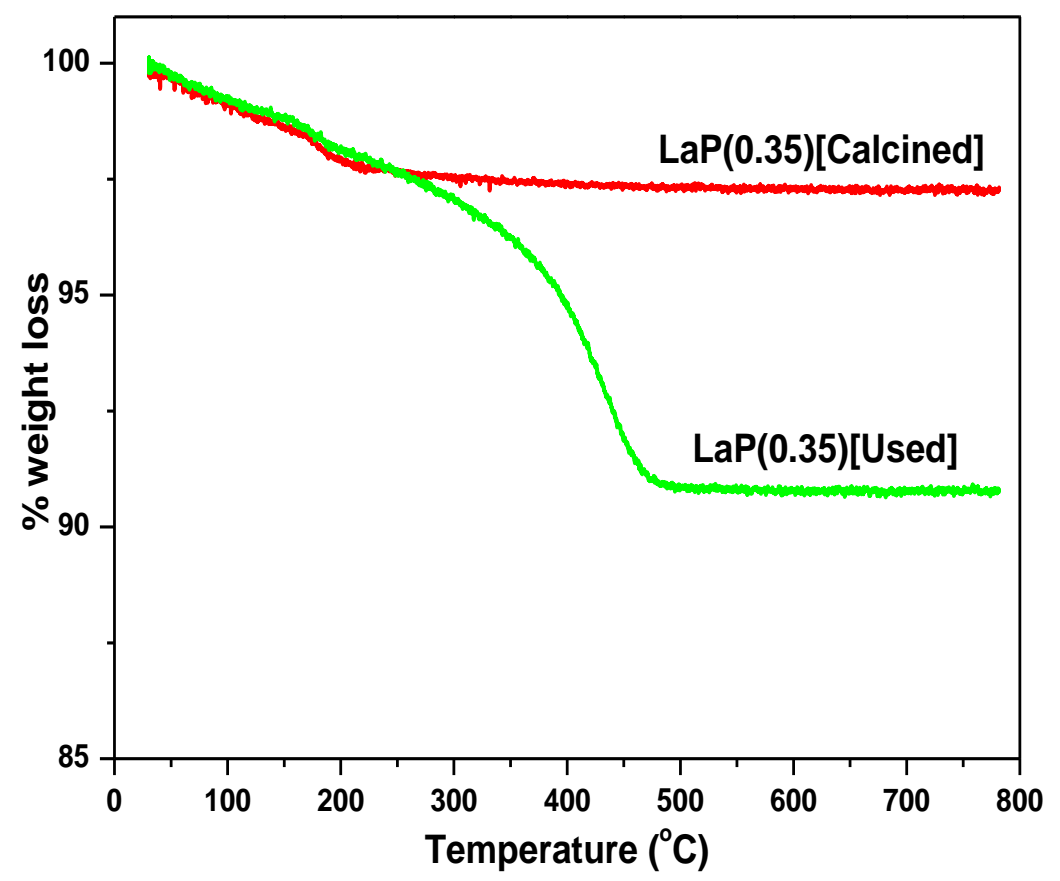

Figure 14. TGA of Calcined and used LaP(0.35)[500].

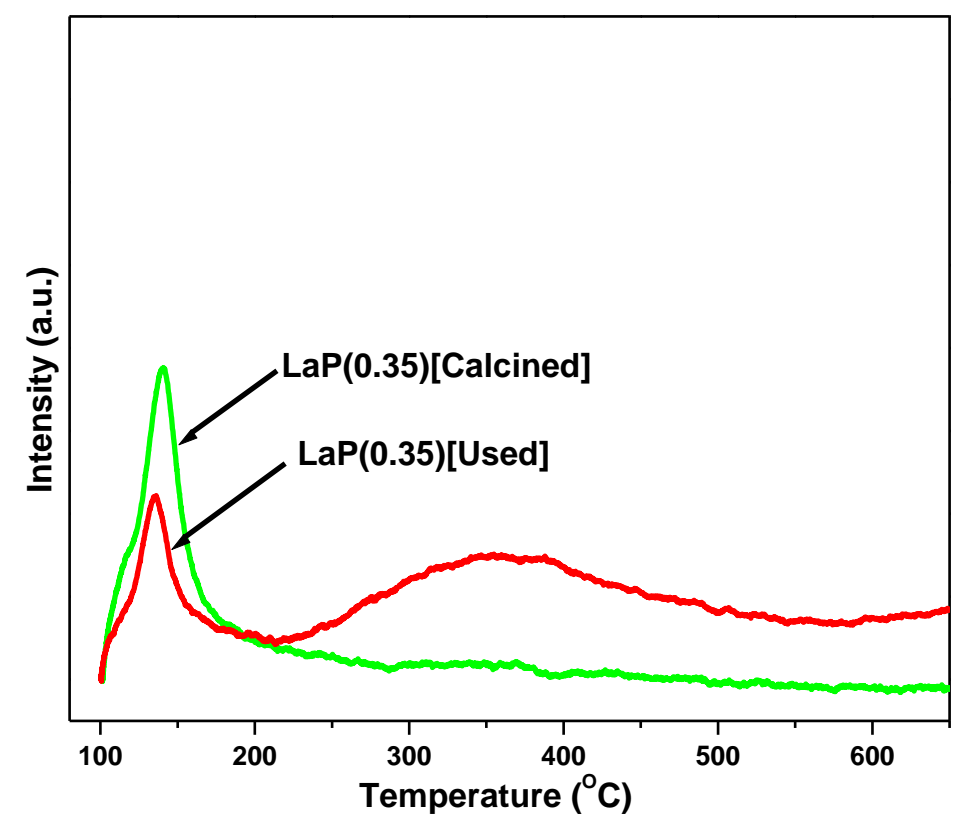

Figure 15. $\mathrm{NH}_{3}$-TPD of Calcined and used LaP(0.35)[500]. 


\section{Conclusion}

A low cost and highly efficient LaP based catalysts were prepared with different La/P mole ratios and tested in LA conversion. The total acidity depends on the phosphate loadings in LaP catalysts and highest acidity was found with the high P content sample. The weak acid sites are important in catalyzing the LA dehydration to AA. Further, not only the lanthanum-phosphorous mole ratio influenced the reaction, but also calcination temperature had significant effect on AA selectivity and LA conversion. The correlation between total acidity and activity were exhibited similar trend. The optimized reaction conditions were determined and also deactivation phenomena were thoroughly studied. The LaP catalyst with $\mathrm{La} / \mathrm{P}$ mole ratio of 0.35 and calcined at $500{ }^{\circ} \mathrm{C}(\mathrm{LaP}(0.35)[500])$ shown superior catalytic performance with complete LA conversion and achieved highest $\sim 74 \%$ AA yield and selectivity compared to all catalysts. Catalyst deactivation occurred due to the formation of carbon/carbonaceous deposits, but regeneration gained complete activity of the LaP catalysts.

\section{References}

[1] Hengfu, S.; Chun, b.; (Charles) Xu. Hydrothermal liquefaction of biomass to fuels and value-added chemicals: Products applications and challenges to develop largescale operations. Biomass and Bioenergy, 2020, 135,105510.

[2] Climent MJ, Corma A, Iborra S (2014) Conversion of biomass platform molecules into fuel additives and liquid hydrocarbon fuels, Green Chem. 16, 516-547. https://doi.org/10.1039/C3GC41492B

[3] Corma A, Iborra S, Velty A (2007) Chemical Routes for the Transformation of Biomass into Chemicals, Chem. Rev. 107, 2411-2502.

https://doi.org/10.1021/cr050989d 
[4] Gallezot P (2012) Conversion of biomass to selected chemical products, Chem. Soc. Rev. 41, $1538-1558$.

https://doi.org/10.1039/C1CS15147A

[5] Bozell JJ, Petersen GR (2010) Technology development for the production of biobased products from biorefinery carbohydrates - the US Department of Energy's "Top 10" revisited, Green Chem. 12, 539-554.

https://doi.org/10.1039/B922014C

[6] Serrano-Ruiz JC, Pineda A, Balu AM, Luque R, Campelo JM, Romero AA, RamosFernández JM (2012) Catalytic transformations of biomass-derived acids into advanced biofuels Catal. Today 195, 162- 168.

https://doi.org/10.1016/j.cattod.2012.01.009

[7] Dusselier M, Wouwe PV, Dewaele A, Makshina E, Sels BF (2013) Lactic acid as a platform chemical in the biobased economy: the role of chemo catalysis, Energy Environ. Sci. 6, 14151442.

https://doi.org/10.1039/C3EE00069A

[8] Jarvinen M, Myllykoski L, keiski R, Sohlo J (2000) Separation of lactic acid from fermented broth by reactive extraction, Bioseparation 9, 163-166.

https://doi.org/10.1023/A:1008183322075

[9] Wang FF, Liu CL, Dong WS (2013) Highly efficient production of lactic acid from cellulose using lanthanide triflate catalysts, Green Chem. 15, 2091-2095.

https://doi.org/10.1039/C3GC40836A

[10] Wang FF, Liu J, Li H, Liu CL, Yang RZ, Dong WS (2015) Conversion of cellulose to lactic acid catalyzed by erbium-exchanged montmorillonite K10, Green Chem. 17, 2455-2463. 
https://doi.org/10.1039/C4GC02131B

[11] Yang L, Su J, Carl S,. Lynam JG, Yang X, Lin H (2015) Catalytic conversion of hemicellulosic biomass to lactic acid in $\mathrm{pH}$ neutral aqueous phase media, Appl. Catal. B: Environ. 162, 149-157.

https://doi.org/10.1016/j.apcatb.2014.06.025

[12] Purushothaman RKP, Haveren JV, Van Es DS, Melian-Cabrera I, Meeldijk JD, Heeres HJ (2014) An efficient one pot conversion of glycerol to lactic acid using bimetallic goldplatinum catalysts on a nanocrystalline $\mathrm{CeO}_{2}$ support, Appl. Catal. B: Environ. 147, $92-$ 100.

https://doi.org/10.1016/j.apcatb.2013.07.068

[13] Sharninghausen LS, Campos J, Manas MG, Crabtree RH (2014) Efficient Selective and Atom Economic Catalytic Conversion of Glycerol to Lactic Acid, Nature Commun.5, 5084.

https://doi.org/10.1038/ncomms6084

[14] Chen L, Ren S, Ye XP (2014) Lactic acid production from glycerol CaO as solid base catalyst, Fuel Process. Technol. 120, 40-47.

https://doi.org/10.1016/j.fuproc.2013.11.019

[15] Xu X, Lin J, Cen P (2006) Advances in the research and development of acrylic acid production form biomass, Chinese J. Chem. Eng. 14, 419-427.

https://doi.org/10.1016/S1004-9541(06)60094-3

[16] Danner H, Urmos M, Gartner M, Braun R (1998) Biotechnological production of acrylic acid from biomass Appl. Biochem. Biotechnol. 70, 887-894.

https://doi.org/10.1007/BF02920199 
[17] Lin MM (2001) Selective oxidation of propane to acrylic acid with molecular oxygen, Appl. Catal. A: Gen. 207, 1-16.

https://doi.org/10.1016/S0926-860X(00)00609-8

[18] Fan Y, Zhou C, Zhu X (2009) Selective Catalysis of Lactic Acid to Produce Commodity Chemicals, Catal. Rev. 51, 293-324.

https://doi.org/10.1080/01614940903048513

[19] Peng J, Li X, Tang C, Bai W (2014) Barium sulphate catalyzed dehydration of lactic acid to acrylic acid, Green Chem. 16, 108-111.

https://doi.org/10.1039/C3GC42028K

[20] Sawicki RA (1988) Catalyst for dehydration of lactic acid to acrylic acid, U.S. Patent 4729978.

[21] Zhang J, Lin J, Cen P (2008) Catalytic dehydration of lactic acid to acrylic acid over sulfate catalysts, The Canadian J. Chem. Eng. 86, 1047-1053.

https://doi.org/10.1002/cjce.20115

[22] Tang C, Peng J, Fan G, Li X, Pu X, Bai W (2014) Catalytic dehydration of lactic acid to acrylic acid over dibarium pyrophosphate, Catal. Commun. 43, 231-234.

https://doi.org/10.1016/j.catcom.2013.10.009

[23] Tang C, Peng J, Li X, Zhai Z, Jiang N, Bai W, Gao H, Liao Y (2014) Strontium pyrophosphate modified by phosphoric acid for the dehydration of lactic acid to acrylic acid, RSC Adv. 4, 28875-28882.

https://doi.org/10.1039/C4RA03398A 
[24] Blanco E, Delichere P, Millet J.M.M, Loridant S (2014) Gas phase dehydration lactic acid to acrylic acid over alkalin-earth phosphate catalysts, Catal. Today 226 185-191. https://doi.org/10.1016/j.cattod.2013.09.059

[25] R.E. Holmen, Production of acrylates by catalytic dehydration of lactic acid and alkyl lactates, US Patent 2859240 (1958) 
[26] Nagaraju N, Kumar V.P, Srikanth A, Rajan N.P, Chary K.V.R (2016) Vapor-phase catalytic dehydration of lactic acid to acrylic acid over nano-crystalline cerium phosphate catalysts, Appl. Petrochem. Res. 6, 367-377.

DOI 10.1007/s13203-016-0150-5

[27] Wang H, Yu D, Sun P, Yan J, Wang Y, Haung H (2008) Rare earth metal modified NaY: Structure and catalytic performance for lactic acid dehydration to acrylic acid, Catal. Commun. 9, 1799-1803. https://doi.org/10.1016/j.catcom.2008.01.023

[28] B. Yan, L.Z. Tao, Y. Liang, B.Q. Xu, Sustainable Production of Acrylic Acid: Catalytic Performance of Hydroxyapatites for Gas-Phase Dehydration of Lactic Acid, ACS Catal. 4, 1931-1943 (2014) https://doi.org/10.1021/cs500388x

[29] Y. Matsura, A. Onda, S. Ogo, K. Yanagisawa, Acrylic acid synthesis from lactic acid over hydroxyapatite catalysts with various cations and anions, Catal. Today 226, 192-197 (2014) https://doi.org/10.1016/j.cattod.2013.10.031

[30] Matsura Y, Onda A, Yanagisawa K (2014) Selective conversion of lactic acid into acrylic acid over hydroxyapatite catalysts, Catal. Commun. 48, 5-10. https://doi.org/10.1016/j.catcom.2014.01.009

[31] Ghantani V.C, Lomate S, Dongre M.K, Umbarkar S.B (2013) Catalytic dehydration of lactic acid to acrylic acid using calcium hydroxyapatite catalysts, Green Chem. 15, 1211-1217 (2013). DOI: $10.1039 / \mathrm{C} 3 \mathrm{GC} 40144 \mathrm{H}$

[32] Yan B, Tao L.Z, Liang Y, Xu B.Q (2014) Sustainable production of acrylic acid: Alkali-ion exchanged beta zeolite for gas phase dehydration of lactic acid, Chem. Sus. Chem. 6, 15681578. 
https://doi.org/10.1002/cssc.201400134

[33] Zhang J, Zhao Y, Pan M, Feng X, Ji W, Au C.T (2011) Efficient acrylic acid production through bio lactic acid dehydration over $\mathrm{NaY}$ zeolite modified by alkali phosphates, ACS Catal. 1, 32-41.

https://doi.org/10.1021/cs100047p

[34] Sun P, Yu D, Tang Z, Li H, Huang H (2010) NaY zeolites catalyze dehydration of lactic acid to acrylic acid: studies on the effects of anions in potassium salts, Ind. Eng. Chem. Res. 49, 9082-90.

https://doi.org/10.1021/ie101093x

[35] Yan B, Mahamood A, Liang Y, Xu B.Q (2016) Sustainable production of acrylic acid: $\mathrm{Rb}^{+}$- and $\mathrm{Cs}^{+}$-exchanged Beta zeolite catalysts for catalytic gas-phase dehydration of lactic acid, Catal. Today 269, 65-73.

https://doi.org/10.1016/j.cattod.2015.10.030

[36] Nafe G. Lopez-Martinez M.A, Dyballa M, hunger M, Traa Y, Hirth T, Klemm E (2015 Deactivation behavior of alkali-metal zeolites in the dehydration of lactic acid to acrylic acid, J. Catal. 329, 413-424

https://doi.org/10.1016/j.jcat.2015.05.017

[37] Yuan C, Liu H, Zhang Z, Lu H, Zhu Q, Chen Y (2015) Alkali-metal-modified ZSM-5 zeolites for improvement of catalytic dehydration of lactic acid to acrylic acid, Chinese J.

Catal. 36, 1861-1866

https://doi.org/10.1016/S1872-2067(15)60970-6 
[38] Zhai Z, Li X, Tang C, Peng J, Jiang N, Bai W, Gao H, Liao Y (2014) Decarbonylation of Lactic Acid to Acetaldehyde over Aluminum Sulfate Catalyst, Ind. Eng. Chem. Res. 53, 10318-10327.

https://doi.org/10.1021/ie500988q

[39] Tang C, Peng J, Li X, Zhai Z, Bai W, Jiang N, Gao H, Liao Y (2015) Efficient and selective conversion of lactic acid into acetaldehyde using a mesoporous aluminum phosphate catalyst, Green Chem. 17, 1159-1166.

DOI: 10.1039/C4GC01779J

[40] Rajesh K, Mukundan P, Krishna Pillai P, Nair V.R, Warrier K.G.K (2004) High-SurfaceArea Nanocrystalline Cerium Phosphate through Aqueous Sol-Gel Route, Chem. Mater. $16,2700-2705$.

https://doi.org/10.1021/cm0499139

[41] Guo Z, Theng D.S, Tang K.Y, Zhang L, Huang L, Borgna A, Wang C (2016) Dehydration of lactic acid to acrylic acid over lanthanum phosphate catalysts: the role of Lewis acid sites, Phys .Chem. Chem. Phys. 18, 23746-23754.

DOI: $10.1039 / \mathrm{C} 6 \mathrm{CP} 04163 \mathrm{~A}$

[42] Onoda H, Nariai H, Moriwaki A, Maki H, Motooka I (2002) Formation and catalytic characterization of various rare earthphosphates, Mater. Chem. 12, 1754-1760. DOI: $10.1039 / \mathrm{B} 110121 \mathrm{H}$

[43] Takita Y, Sano K, Muraya T, Nishiguchi H, Kawata N, Ito M, Akbay T, Ishihara T (1998) Oxidative dehydrogenation of iso-butane to iso-butene II. Rare earth phosphate catalysts Appl. Catal. A: Gen. 170, 23-31.

https://doi.org/10.1016/S0926-860X(98)00043-X 
[44] Ho LN, Nishiguchi H, Nagaoka K, Takita Y (2006) Synthesis and characterization of a series of mesoporous nanocrystalline lanthanides phosphate, J. Porous Mater. 13, 237-244. DOI 10.1007/s10934-006-8010-9

[45] Rajesh K, Shajesh P, Seidel O, Mukundan P, Warrier K. G. K (2007) A Facile Sol-Gel Strategy for the Synthesis of Rod-Shaped Nanocrystalline High-Surface-Area Lanthanum Phosphate Powders and Nanocoatings, Adv. Funct. Mater. 17, 1682-1690. https://doi.org/10.1002/adfm.200600794

[46] Rajesh K, Sivakumar B, P Pillai.K, Mukudhn P, Warrier K.G.K, Nair V.R (2004) Synthesis of nanocrystalline lanthanum phosphate for low temperature densification to monazite ceramics, Mater. Lett. 58 1687-1691

https://doi.org/10.1016/j.matlet.2003.11.028

[47] Lucas S, Champion E, Bernache-Assollant D, Leroy G (2004) Rare earth phosphate powders $\mathrm{RePO}_{4} \cdot \mathrm{nH}_{2} \mathrm{O}(\mathrm{Re}=\mathrm{La}$, Ce or Y)-Part-II. Thermal behavior, J. Solid State Chem. $177,1312-1320$.

https://doi.org/10.1016/j.jssc.2003.11.004

[48] Chai Z, Suo Q, Wang H, Wang X (2013) Mesoporous lanthanum phosphate nano structures containing $\mathrm{H}_{3} \mathrm{PO} 4$ as superior electrolyte for PEM fuel cell, RSC Adv. 3. 21928-21935. https://doi.org/10.1039/C3RA42094A

[49] Rajan N.P, Rao G.S, Kumar V.P, Chary K.V.R (2014) Vapour phase dehydration of glycerol over VPO catalyst supported on zirconium phosphate, Catal. Sci. Technol. 4, 8192.

DOI: $10.1039 / C 3 C Y 00430 A$ 
$\mathrm{N}$. Nekkala designed the experiments, conducted research work, compiled data and wrote the manuscript. B. Putrakumar conceptualize the work, designed experiment, data interpretation and wrote the manuscript. G. Srinivasarao made analysis, complied data and interpretation of the results. P.K. Seelam conducted analysis, wrote the manuscript, drafting the work and revising. S.K. Hussain conducted research work and complied data on activity and characterisation. P. Bhanuchander conducted research and analysis on catalysts characterisation. VRC Komandur improved the language and made final revision and approval.

\section{Contributions}

Kanokphorn Sangkharak designed the experiment, conducted research work, compiled data and wrote the manuscript. Kamolphan Chookun conducted research work pertaining to bioethanol, Jutamas Numreung conducted research work pertaining to biodiesel, and Poonsuk Prasertsan is mentor.

conception or design of the work; or the acquisition, analysis, or interpretation of data; or the creation of new software used in the work;

Drafting the work or revising it critically for important intellectual content; AND Final approval of the version to be published; 